\title{
Conceptual design of cogeneration plants under a resilient design perspective: Resilience metrics and case study
}

\author{
José Alexandre Matelli ${ }^{\mathrm{a}, \mathrm{b}, *}$, Kai Goebel ${ }^{\mathrm{a}, \mathrm{c}}$ \\ a NASA Ames Research Center, Intelligent Systems Division, Discovery and Systems Health, Moffett Field, CA, USA \\ ${ }^{\mathrm{b}}$ São Paulo State University (UNESP), School of Engineering, Department of Energy, Guaratinguetá, SP, Brazil \\ ${ }^{\mathrm{c}}$ Luleå University of Technology, Division of Operation and Maintenance Engineering, Luleå, Sweden
}

\section{H I G H L I G H T S}

- Resilience of cogeneration plant conceptual design is analyzed through complex network theory.

- A novel resilient design framework based on Monte Carlo simulations is developed.

- New metrics of resilience are proposed based on the resilient design framework.

- Results from the framework are more consistent than those from complex network theory.

\section{A R T I C L E I N F O}

\section{Keywords:}

Resilient design

Cogeneration

Conceptual design

Complex engineering systems

Simulation

\begin{abstract}
A B S T R A C T
The conceptual design phase is the first step in the design process of an engineering system. Most engineering systems, including cogeneration plants, may and likely will experience some malfunctions during its life cycle. The metrics typically considered in the conceptual design phase (and for analysis and optimization) of energy systems are cost, efficiency and environmental impacts. Quite rarely are operational considerations about malfunctions integrated during the conceptual design phase. Resilient design, or design for resilience, addresses this gap as illustrated here in the area of energy conversion and conservation of energy processes by examining the conceptual design of a cogeneration plant. Resilient design is a relatively new research field where the engineering system is designed such that it can optimally recover from failures. The main challenge is to quantify the resilience in early design phases, since there is not much detailed information about system components available at this point. To address these challenges, this paper introduces a novel resilient design framework that uses new metrics within a Monte Carlo-based assessment approach. The framework is exercised on conceptual designs of cogeneration plants. Results from this framework are compared against those from a methodology based on complex networks theory that has been previously suggested in the literature. The former presented more consistent results than the latter and we discuss the differences. Results also show that the concept with higher efficiency was not the one with higher resilience. Finally, we discuss how to integrate specific failure probabilities information into the framework (should that information be available), and deliberate on relations between resilience, fault handling strategies and design requirements.
\end{abstract}

\section{Introduction}

Cogeneration is one of the most attractive alternatives realization of power plants that promote the rational use of energy resources. A cogeneration plant simultaneously generates power and useful heat from the same fuel and can be seen as a thermal system, i.e., a collection of components with interrelated performance on which fluids, heat and work are transported and converted. Gas turbines and reciprocating internal combustion engines are the most used prime movers in natural gas-fired cogeneration plants. Fuel cells fed by hydrogen obtained from natural gas reforming are state-of-the-art technologies for cogeneration, but they are still not enough mature to be commercially competitive [1].

Design teams of cogeneration plants often seek a conceptual solution for high efficiency, low capital cost and low emissions, as reported in [2-5]. However, a fault-tolerance analysis is rarely carried out during conceptual design because detailed knowledge of system components and their performance criteria are not yet available [6],

\footnotetext{
* Corresponding author at: NASA Ames Research Center, Intelligent Systems Division, Discovery and Systems Health, T35-B, Moffett Federal Airfield, CA 94035, USA.

E-mail addresses: matelli@feg.unesp.br, jose.a.matelli@nasa.gov (J.A. Matelli), kai.goebel@nasa.gov, kai.goebel@ltu.se (K. Goebel).
} 


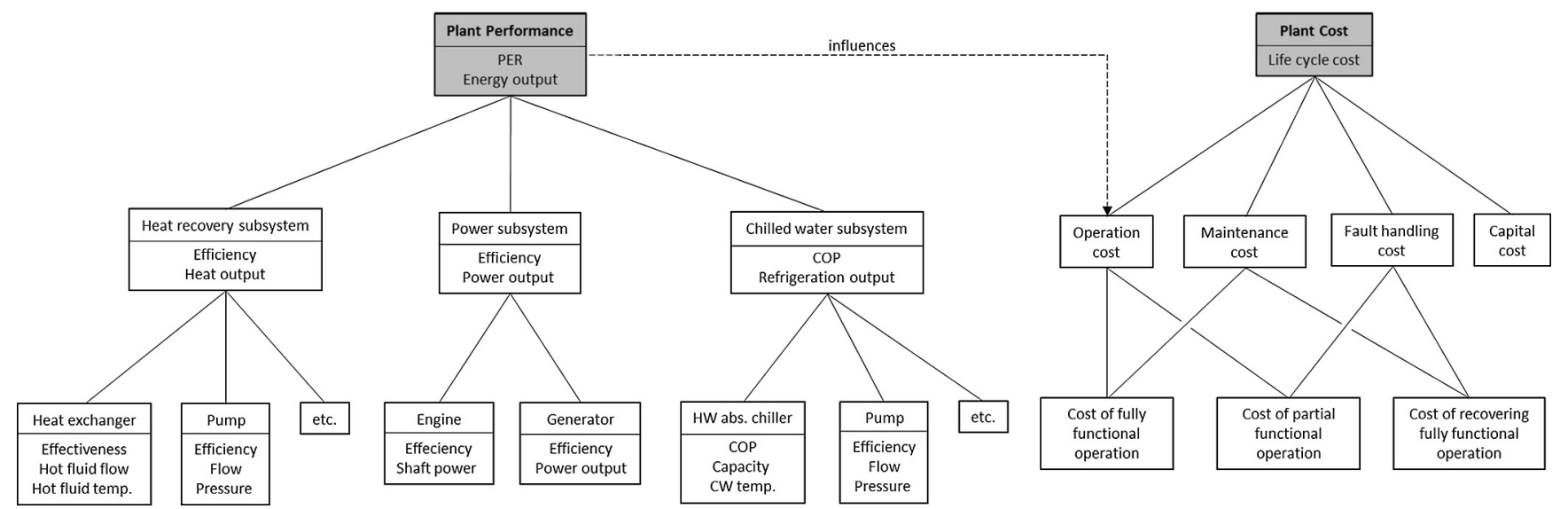

Fig. 1. Requirements flow-down.

(notwithstanding the recently proposed methodology for optimization of component reliability of heat supply system [7]). In particular, having accurate failure rates or failure probabilities depends on large amount of historic operational data for all the components, information often difficult to obtain when fleet sizes are small or where no sufficiently long operational history exists. Since fault-tolerance analysis is rarely carried out during the early design phases, resilient design - or design for resilience - covers this gap for system related to energy conversion and conservation of energy processes, including for the conceptual design of energy systems. Resilient design is a relatively new research field where the engineering system is designed such that it can maintain maximally operational states despite the presence of failures. A key aspect is the ability to quantify system resilience in order to support the design team during the conceptual design stage. However, available engineering quantification metrics still exhibit very little standardization and agreement on a general quantifiable measure remains a challenge [8].

There are several definitions of resilience found in the literature. For the purposes of this work, the one presented by Heimes [9] fits best: resilience is the ability of the system i) to withstand a major disruption within acceptable degradation parameters and ii) to recover within an acceptable time and composite costs and risks. The second part of Heimes' resilience definition is closely related to fault handling strategies. It should be noted that integrating specific fault handling strategies during the conceptual design is outside the scope of the present work. We focus here on the assessment of resilience and only discuss the main aspects of fault handling strategies during design phase.

A number of intelligent computational tools for cogeneration plant design including knowledge-based tools [10-14] are found in the literature. Methods based on linear and non-linear programming that support thermal systems design and analysis are well established [15-18]. The goal of the conceptual design of any mechanical system is to generate several alternatives that are able to meet the design requirements [19], which is a very product-oriented point of view. For complex engineering systems, such as cogeneration plants, design requirements should be specified in a verifiable and hierarchical way known as requirements flow-down. Requirements flow-down is a best practice that helps engineers maintain clarity and structure while they perform decomposition of high level system requirements into functional, physical and component design requirements [20].

A simplified requirements flow-down for natural-gas fueled cogeneration plants is shown in Fig. 1. High level requirements pertain to performance and cost. That is, the cogeneration plant should meet energy demands with high efficiency ${ }^{1}$ and low cost. The plant

\footnotetext{
${ }^{1}$ In this work, plant efficiency is expressed as Primary Energy Rate (PER), a proper parameter to quantify efficiency of combined power and refrigeration systems [21].
}

performance requirement is split into subsystems performance requirements and each subsystem requirement is split into individual component performance requirements. In a similar way, cost requirement is split into operation cost, maintenance cost and fault handling cost. Depending on how detailed the flow-down should be, each of these lower level requirements can be split into further lower levels. Organizing the requirements as a flow-down diagram can help in understanding the role of some requirements for plant resilience and even lead to establishing new metrics for resilience.

Willis and Loa [22] present several metrics for resilience of energy systems used that can apply to different levels of the requirements flowdown diagram. As a result, some of these metrics have a more global viewpoint, such as knowing how resilience affects economic output stemming from hypothetical disasters that compromise the energy infrastructure of a region, for example. For a local cogeneration plant it may be more important to know how many spare parts are in stock and what options exist for backup power generation [22].

Besides these more management-oriented metrics, resilience can also refer to formal mathematical parameters that quantify the system ability to withstand disruption and its capability to function as required. Providing metrics for resilience has been one of the major research thrusts in computer networks over the last decades. The study of network topology from this area brings some interesting insights into the design of complex engineering systems, as shown by Mehrpouyan et al. [6]. Although resilience has been explored in several engineering domains [23-28], resilient design of energy systems, such as cogenerations plants, is still a somewhat open domain. To address this need, this paper approached the conceptual design of natural gas-fueled cogeneration plants from a resilient design perspective. To do so, we develop an original resilient design framework based on a Monte Carlo approach, from which we propose new metrics to assess the resilience of four different cogeneration plants during the conceptual design phase. The plant designs are generated from an available knowledgebased system. Results obtained from the framework are compared to those obtained from an analytical methodology adapted from complex networks analysis found in the literature. The relationship between resilience and plant requirements is also discussed, as well as integrating more specific failure probability information that might be available, limitations and further development of this research.

\section{Methodology}

\subsection{Concepts generation}

Four different cogeneration plant concepts are generated for the present resilience analysis. The concepts are provided by a previously developed knowledge-based system (KBS) [13]. The KBS infers new 
Table 1

Information required by the KBS to generate concepts.

\begin{tabular}{lll}
\hline Parameter & Value & Unit \\
\hline Local average temperature & 18 & ${ }^{\circ} \mathrm{C}$ \\
Local altitude & 670 & $\mathrm{~m}$ \\
Maximum power demand & 1500 & $\mathrm{~kW}$ \\
Minimum power demand & 900 & $\mathrm{~kW}$ \\
Electrical energy consumption $^{\text {Chilled water demand }}$ & 28 & $\mathrm{MWh}$ \\
Daily operation $^{\mathrm{a}}$ & 1407 & $\mathrm{~kW}$ \\
Weekly operation $_{\text {Electric connection scheme }}$ & 24 & $\mathrm{~h} /$ day \\
Chilled water storage (optional) & 7 & days/week \\
\end{tabular}

a Also corresponds to the time period of the electrical energy consumption.

concepts from basic technical information summarized in Table 1.

The KBS inference process combines different pre-determined subsystem, each with a specific function. The subsystems combination is subject to the laws of thermodynamics, so that a generated concept is an allowed combination of subsystems. The KBS also scales all components and calculates overall performance parameters, such as power output, chilled water production and efficiency [13].

The two concepts depicted in Figs. 2 and 3 differ in the number of prime movers, but are otherwise basically the same. Power is generated in a generator $(G)$ coupled to a reciprocating internal combustion engine (E). Both generator and external grid are connected to a bus bar, which is connected to the power load that the plant should meet. All plant ancillary systems (pumps, fans, control panels etc.) are also connected to the bus bar, but such connections are not presented in the diagrams for the sake of simplicity. Heat from engine exhaust gases are rejected to the environment, as long as heat from jacket water is recovered in a heat exchanger (HEX) in order to provide hot water to a single effect absorption chiller (HWAC), which should meet the chilled water demand. A radiator (R) allows the engine to operate when HWAC is out of service. A mechanical-driven chiller (MDC) can be used either for backup or supplement purposes. Heat from condenser of both chillers is rejected to the environment through a cooling tower (CT).

The concepts depicted in Figs. 4 and 5 also differ in the number of prime movers, but they are additionally based on gas turbine instead of reciprocating engines. Power is generated in a generator $(G)$ coupled to a gas turbine (GT). A bus bar fed by the generator and external grid is connected to the power load that the plant should meet. Plant ancillary systems are also connected to the bus. Heat from turbine exhaust gases is recovered in a heat recovery steam generator (HRSG) in order to provide steam to a double effect absorption chiller (SAC), which should meet the chilled water demand. A mechanical-driven chiller (MDC) is used for backup purposes. Heat from condenser of both chillers is rejected to the environment through a cooling tower (CT).

\subsection{Resilient design framework}

In order to evaluate and compare the resilience of the concepts described in Section 2.1, a resilient design framework is developed. The framework is embedded in a tool for stochastic failure propagation simulation. The underlying idea is based on the Monte Carlo approach, i.e., to run several simulations for each plant and verify which one is able to keep working for longer, on average, in the presence of randomly injected failures. Here, "keep working" means that the plant is able to fully or partially meet power and chilled water loads. The flow diagram of the simulation tool is shown in Fig. 6.

The simulation tool works as follows: first, a non-failed component $i$ is randomly assigned as candidate subject to failure. Component $i$ has a known probability $p_{i}$ to work properly (the higher the component quality, the higher $\left.p_{i}\right)$. Then, a failure probability $p_{b}(t)$ for time $t$ is randomly assigned. If $p_{b}(t) \leqslant p_{i}$, component $i$ does not fail and a new candidate to failure is randomly chosen. If $p_{b}(t)>p_{i}$, component $i$ fails and it is determined whether this failure propagates to component $j$. If it does, it is checked whether failure in $j$ propagates to component $k$ and

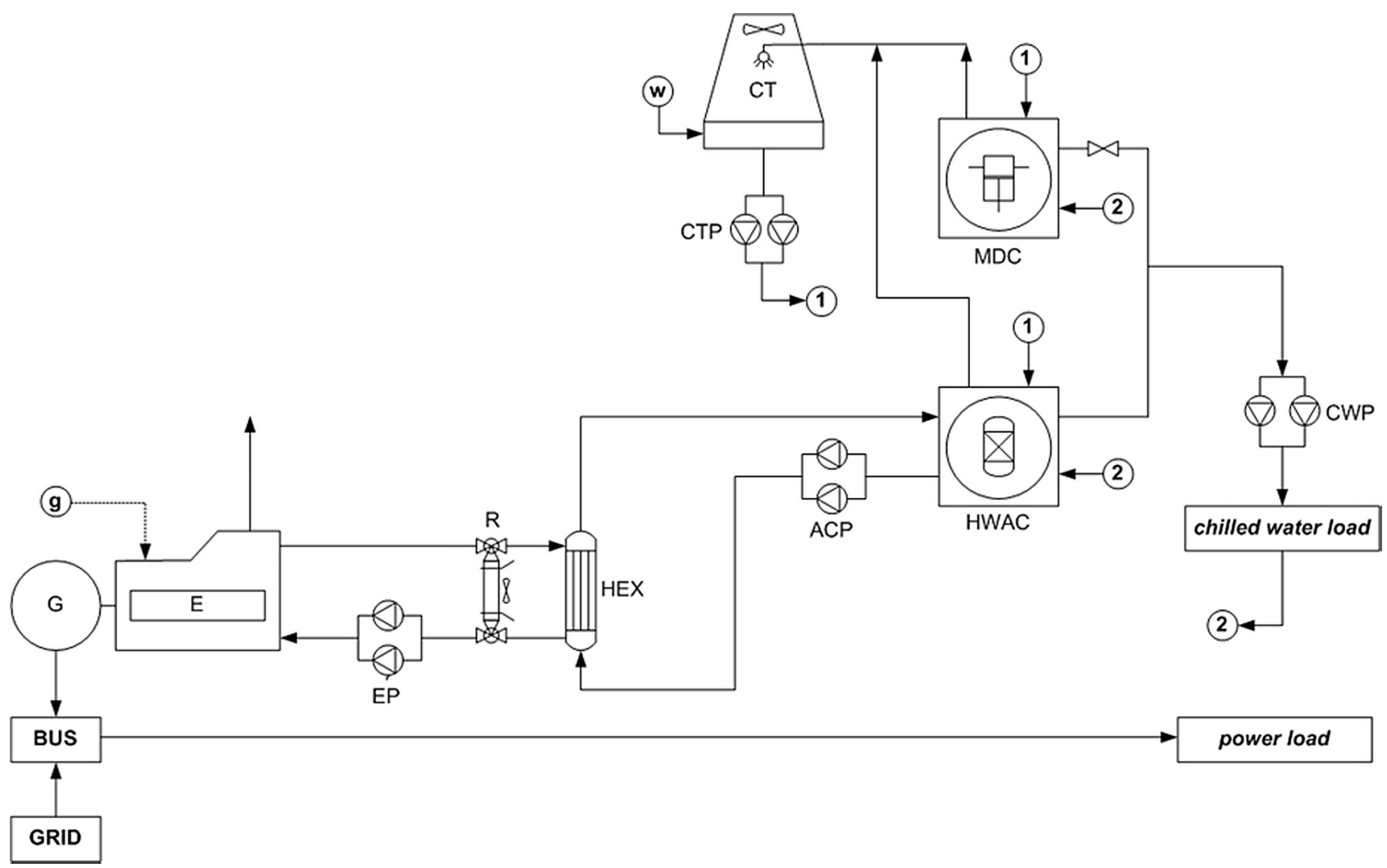

Fig. 2. C\#1: concept based on one reciprocating internal combustion engine. 


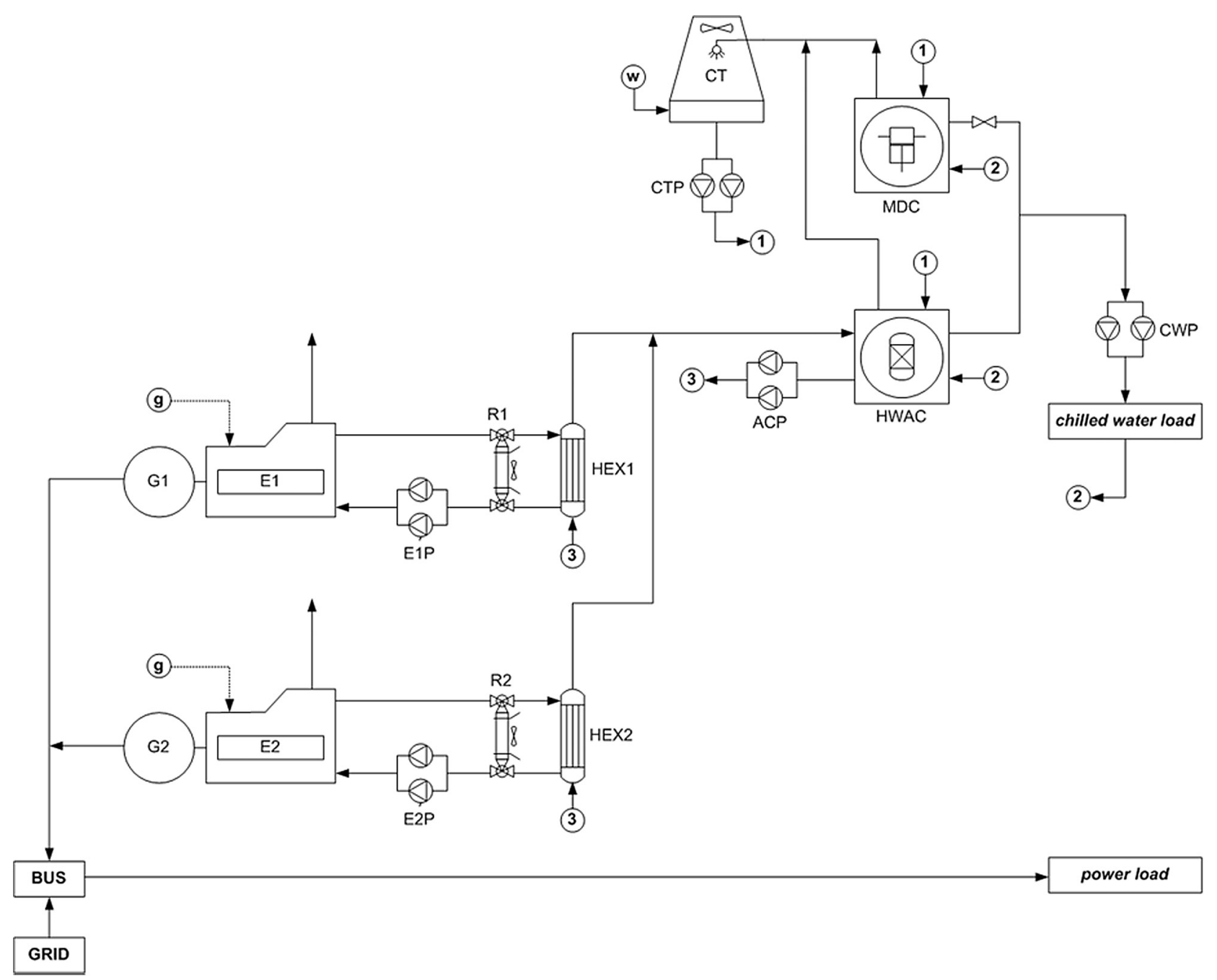

Fig. 3. C\#2: concept based on two reciprocating internal combustion engines.

so on, until failure propagation eventually stops. Failure propagation is evaluated based on a rule that is executed whenever its premises are satisfied. The premises of the rule are that one of two objects [component] has failed. The objects' type must differ, meaning that a failure must not propagate to a physical redundancy. The rule for failure propagation is depicted in Fig. 7. Fig. 8 shows the associated procedure [propagates] for the non-failed component that evaluates the failure propagation.

Successive execution of the failure propagation rule results in a collection $c(t)$ of failed components at time $t$. If $c(t)$ causes failure of the whole plant, i.e., it renders unable to meet power and chilled water load, simulation will stop at time $t$; otherwise, resilient operating time $r$ is updated and a new candidate to failure is randomly chosen. The simulation ends with one out of three possible plant operating states:

Normal: no component is failed at time $t=T$ and resilient operating time results in $r=0$;

Failed: there are failed components and the plant is not capable to meet power and chilled water loads at time $t<T$. Resilient operating time results in $r \leqslant t$;

Resilient: there are failed components, but the plant is capable to partially meet at least one of the loads at time $t=T$. Resilient operating time results in $r \leqslant T$.

Each plant is simulated $N$ times, each simulation set for $T$ operating hours with $p_{i}$ attributed to the respective component $i$. The plurality of $p_{i}$ attributed to the respective component $i$ forms a set of probabilities $p_{i}$ denoted $\left\{p_{i}\right\}$. Due to the stochastic nature of the simulations, it is important to keep them as fair and unbiased as possible, not only to assure a "fair game", but also to make sure that the concepts differ only in their configuration. In order to do so, it is proposed to consider an ideal failure propagation mechanism based on the following assumptions:

a. All concepts have the same $\left\{p_{i}\right\}$;

b. $\left\{p_{i}\right\}$ is constant and time-independent;

c. a failure in a component is instantaneously propagated to any other component connected to the failed component, regardless of the nature of the connection;

d. a failure in a component propagates to any other component connected to the failed component with a constant, time-independent probability equal to 1 ;

e. no partial failure of any component is admitted;

f. no repair action is taken.

Five metrics for resilience are being considered within this framework:

i. Fraction of simulations that result in resilient operation: this metric can be interpreted as the probability of a design concept exhibiting resilient operation during a period $T$ for a given $\left\{p_{i}\right\}$ and infinite number of simulations (Eq. (1)). A high value of $p_{r}\left(T,\left\{p_{i}\right\}\right)$ indicates high resilience. 


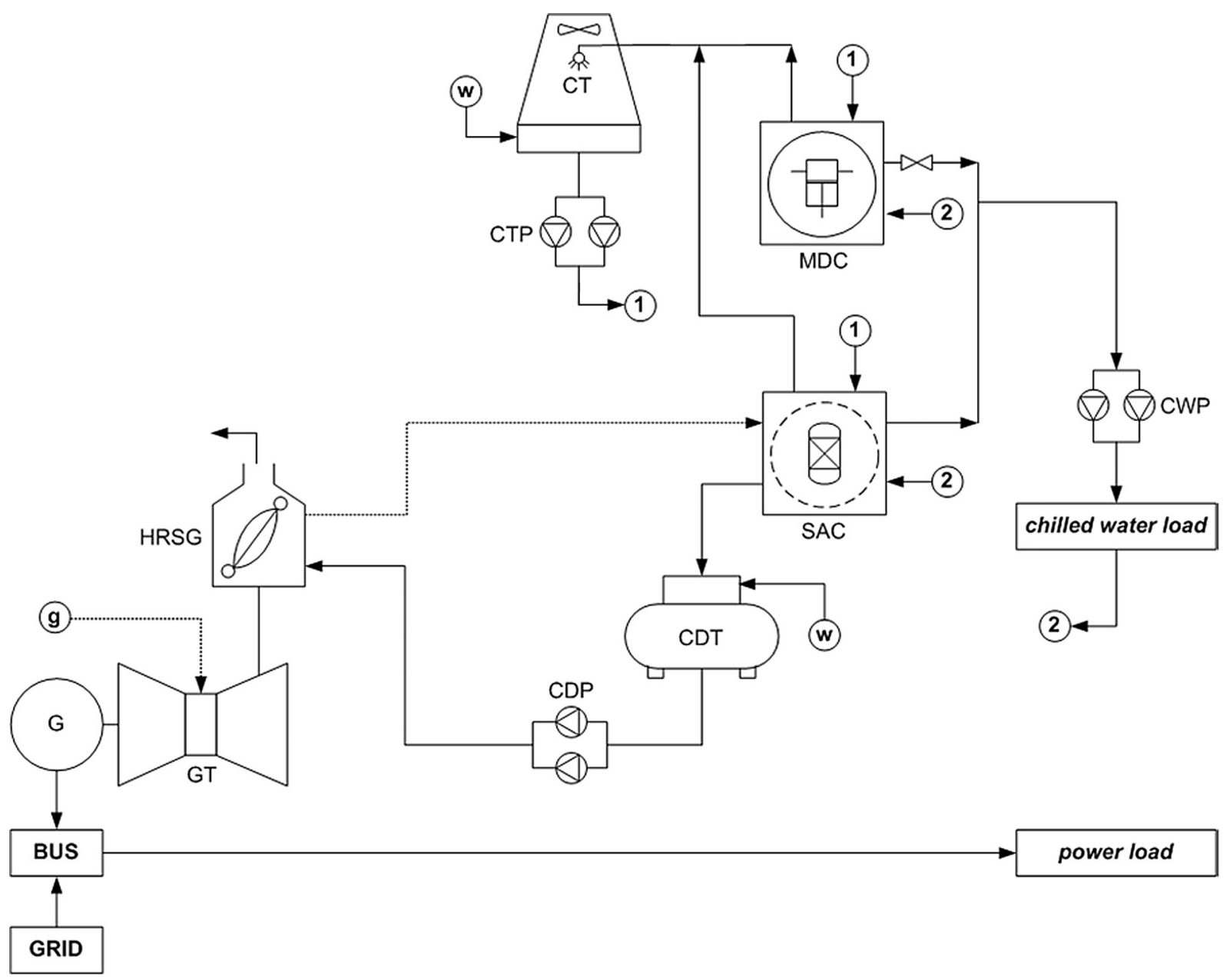

Fig. 4. C\#3: concept based on one gas turbine.

$$
p_{r}\left(T,\left\{p_{i}\right\}\right)=\lim _{N \rightarrow \infty}\left(N_{r} / N\right)
$$

ii. Resilient operating time: this metric is defined as the weighted average of the resilient operating time $r$ for all simulations $k$ that has at least one failed component for a given $\left\{p_{i}\right\}$, i.e., all simulations $k$ on which $t_{k}=T$ and $0<r_{k} \leqslant t_{k}$. (Eq. (2)). The weighting factor is $p_{r}\left(T,\left\{p_{i}\right\}\right)$. When comparing different concepts, the one with the higher resilient operating time is the most resilient.

$\bar{r}\left(T,\left\{p_{i}\right\}\right)=\frac{p_{r}\left(T,\left\{p_{i}\right\}\right)}{N_{r}} \sum_{k=1}^{N_{r}} r_{k} \quad\left\{k \mid t_{k}=T, 0<r_{k} \leqslant t_{k}\right\}$

iii. Time until failure: average time until failure is defined as the average of the total operating time $t_{k}$ for all simulations that result in a complete failure for a given $\left\{p_{i}\right\}$, i.e., all simulations $k$ for which $t_{k}<T$ and $r_{k} \leqslant t_{k}$. (Eq. (3)). The higher this metric, the higher the resilience.

$\bar{f}\left(T,\left\{p_{i}\right\}\right)=\frac{1}{N_{f}} \sum_{k=1}^{N_{f}} t_{k} \quad\left\{k \mid t_{k}<T, r_{k} \leqslant t_{k}\right\}$

iv. Fraction of simulations that result in failed operation: similar to $p_{r}$, this metric expresses the probability of a concept failing in a period of time close to $\bar{f}<T$ for a given $p_{i}$ and infinite number of simulations (Eq. (4)). Here, a high value of $p_{f}$ indicates low resilience.

$p_{f}\left(T,\left\{p_{i}\right\}\right)=\lim _{N \rightarrow \infty}\left(N_{f} / N\right)$ v. Normalized resilience index: First, we define the average operating time $\bar{t}\left(T,\left\{p_{i}\right\}\right)$ as the weighted average between the average operating time of all simulations on which $t<T$ (i.e., failed simulations) and the average operating time of all simulations on which $t=T$ (i.e., normal and resilient simulations). The weights are $p_{f}\left(T,\left\{p_{i}\right\}\right)$ and its complement, respectively (Eq. (5)).

$\bar{t}\left(T,\left\{p_{i}\right\}\right)=p_{f} \bar{f}+\left(1-p_{f}\right) T$

For convenience, the average operating time is divided by $T$, defining then the normalized resilience index $\rho\left(T,\left\{p_{i}\right\}\right)$ (Eq. (6)).

$\rho\left(T,\left\{p_{i}\right\}\right)=\bar{t}\left(T,\left\{p_{i}\right\}\right) / T$

\section{Results}

\subsection{Thermal performance}

Basic performance results provided by the KBS developed by Silva et al. [13] are shown in Table 2. Prime mover and chillers are selected by the KBS from a database comprised of actual machines.

It can be seen from Table 2 that concepts $\mathrm{C} \# 1$ and $\mathrm{C} \# 2$ require the mechanical-driven chiller to supplement the chilled water load because the refrigeration rated capacity of the absorption chiller is lower than the chilled water demand presented in Table 1 . As a result, concepts 1 and 2 require imported power from the grid to drive the mechanical chiller. Concepts $\mathrm{C \#} 3$ and $\mathrm{C \# 4}$, on the other hand, do not require imported power since the refrigeration rated capacity of the chiller is 


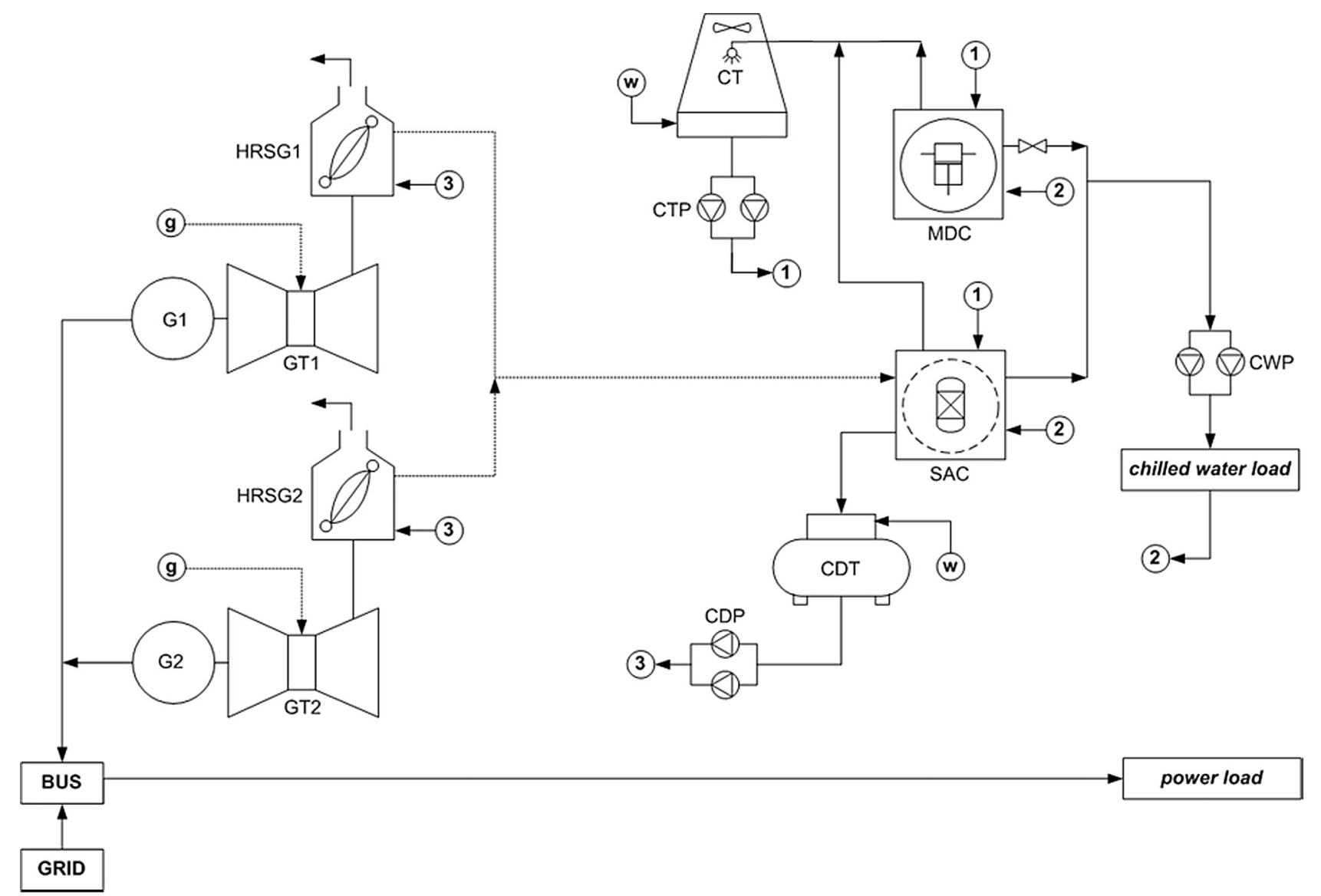

Fig. 5. C\#4: concept based on two gas turbines.

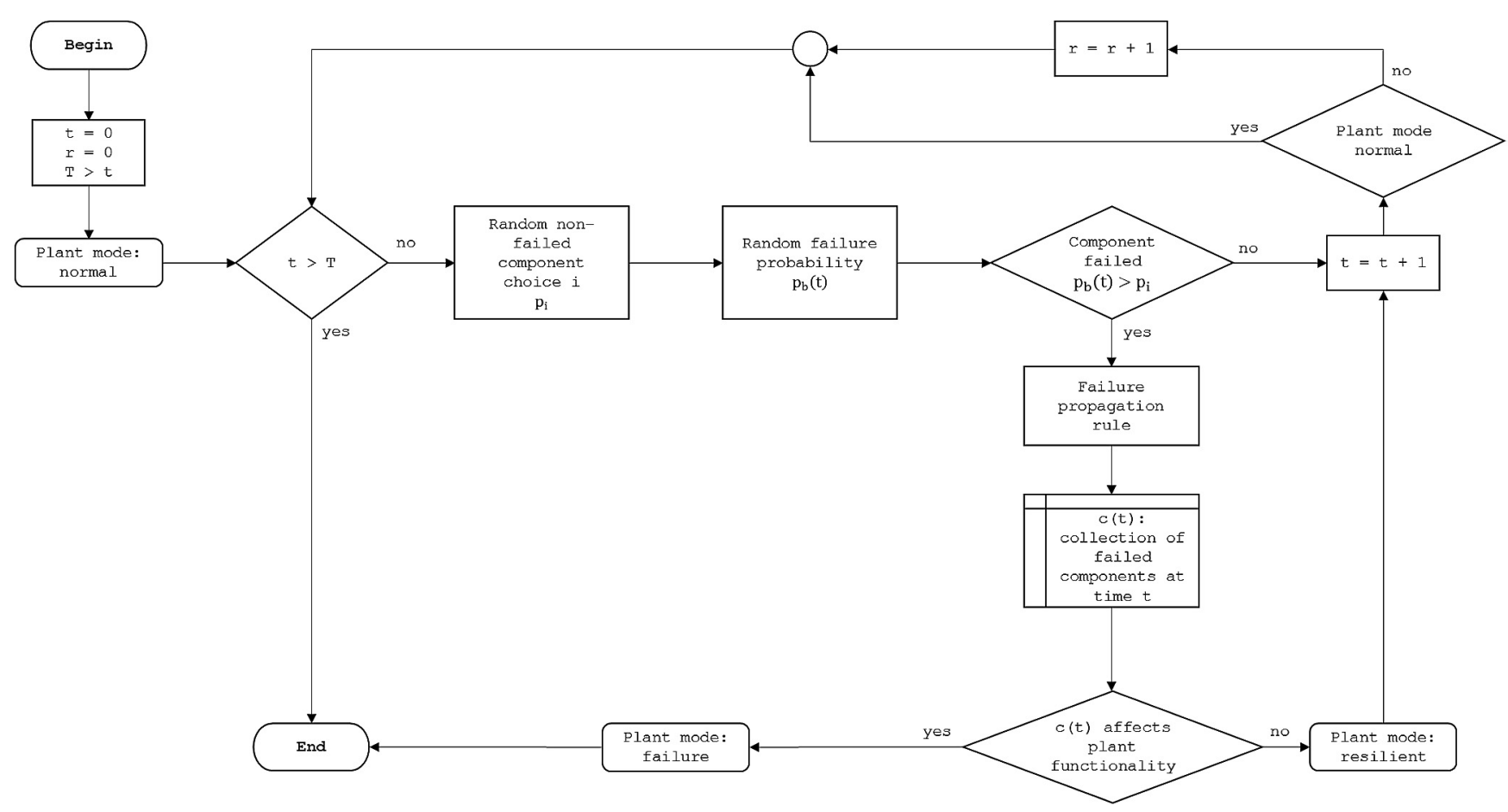

Fig. 6. Stochastic failure propagation simulation tool. 


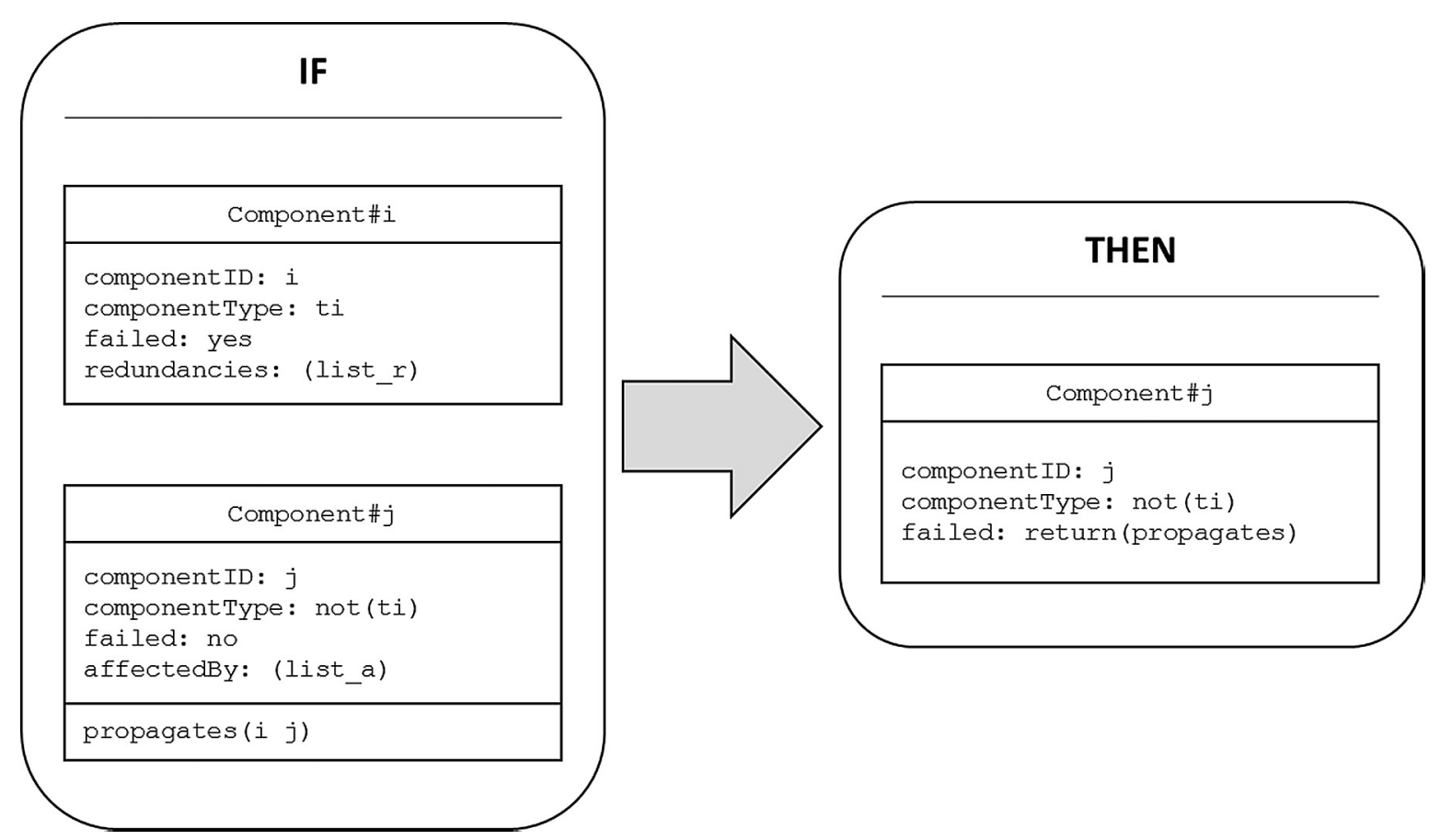

Fig. 7. Rule for failure propagation.

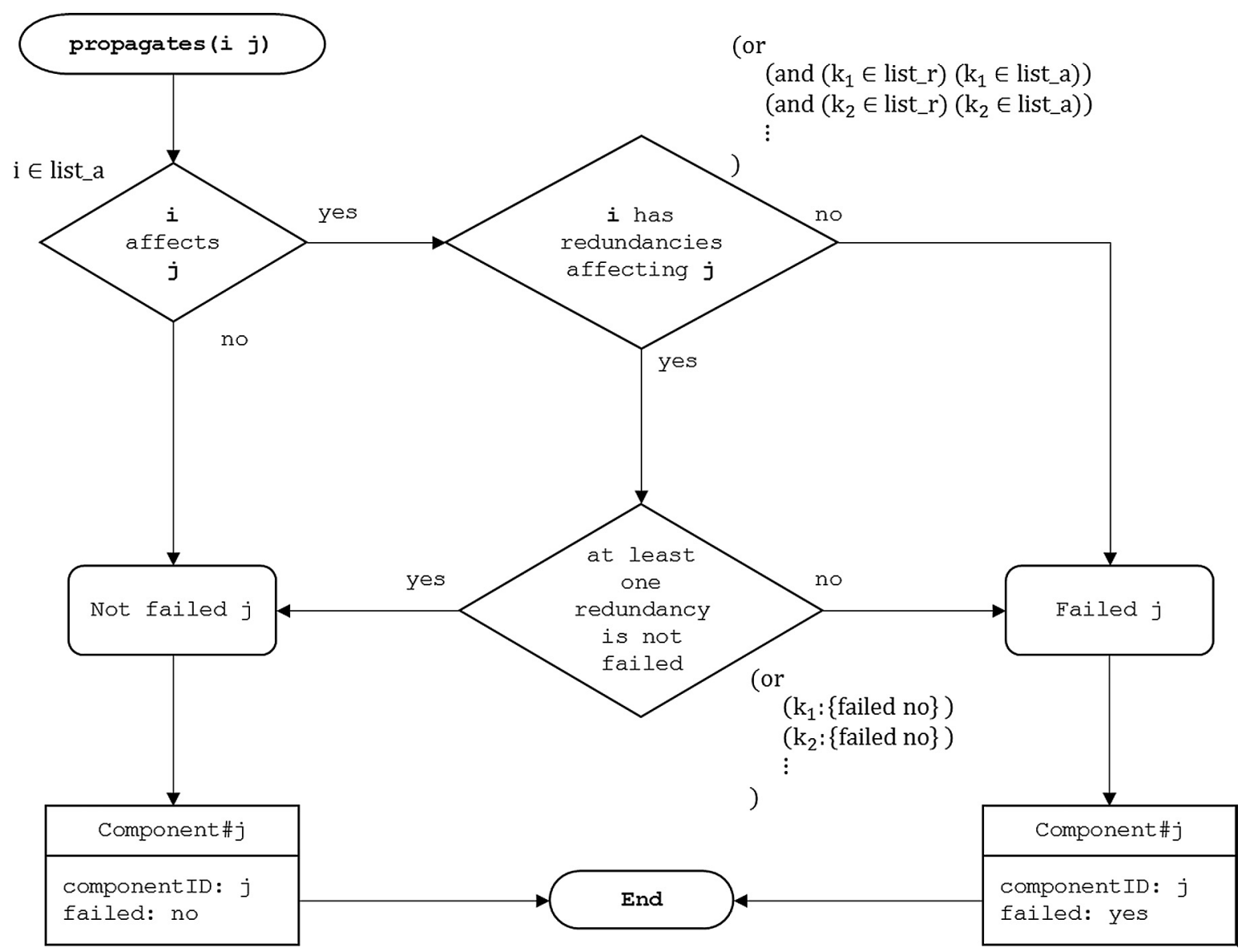

Fig. 8. Procedure [propagates].

greater than the chilled water demand. In these cases, the mechanical chiller serves as backup. Despite the need to import power from the grid, primary energy rate (PER) from concepts $\mathrm{C} \# 1$ and $\mathrm{C \# 2}$ are much greater than concepts $\mathrm{C \# 3}$ and $\mathrm{C \# 4}$. Thus, purely from a thermal performance point of view, concept C\#1 should be the preferred design choice, because it presents the highest PER and likely the lowest capital cost since it has less components. 
Table 2

Performance results for each concept.

\begin{tabular}{|c|c|c|c|c|}
\hline Parameter & $\mathrm{C} \# 1$ & $\mathrm{C} \# 2$ & $\mathrm{C} \# 3$ & $\mathrm{C} \# 4$ \\
\hline Prime mover & $1 \times$ Waukesha $12 \mathrm{~V}$-AT27GL & $2 \times$ Waukesha 8L-AT27GL & $1 \times$ Solar Centaur 40 & $2 \times$ Solar Saturn 20 \\
\hline Absorption chiller & $1 \times \mathrm{LG}$ B160AL & $1 \times$ LG B190AL & $1 \times$ LG LSH-G050 & $1 \times$ LG LSH-G110 \\
\hline Mechanical-driven chiller & $1 \times$ LG LTP-040 & $1 \times$ LG LTP-040 & $1 \times$ LG LTP-040 & $1 \times$ LG LTP-040 \\
\hline \multicolumn{5}{|l|}{ Rated capacity $(\mathrm{kW})$} \\
\hline Power (W) & 2100.0 & 2800.0 & 3515.0 & 2420.0 \\
\hline \multicolumn{5}{|l|}{ Refrigeration (Q) } \\
\hline Absorption & 567.7 & 668.2 & 1758.5 & 3868.7 \\
\hline Mechanical-driven & 1406.8 & 1406.8 & 1406.8 & 1406.8 \\
\hline \multicolumn{5}{|l|}{ Average output (kW) } \\
\hline Power & 1166.7 & 1166.7 & 1166.7 & 1166.7 \\
\hline Refrigeration & 1406.8 & 1406.8 & 1406.8 & 1406.8 \\
\hline \multicolumn{5}{|l|}{ Efficiency $^{\mathrm{a}}$} \\
\hline Prime mover ${ }^{\mathrm{b}}$ & 0.3314 & 0.3181 & 0.1808 & 0.1806 \\
\hline Absorption chiller & 0.7020 & 0.7015 & 1.219 & 1.220 \\
\hline Mechanical-driven chiller & 5.024 & 5.024 & 5.024 & 5.024 \\
\hline Fuel consumption $\mathrm{m}_{\mathrm{f}}(\mathrm{kg} / \mathrm{s})^{\mathrm{c}}$ & 0.07491 & 0.07803 & 0.1373 & 0.1376 \\
\hline Imported power $(\mathrm{kW})$ & 176.8 & 155.6 & 0.0 & 0.0 \\
\hline PER $^{\mathrm{d}}$ & 0.6959 & 0.6731 & 0.3988 & 0.3980 \\
\hline
\end{tabular}

${ }^{\text {a }}$ COP for refrigeration machines.

${ }^{\mathrm{b}}$ Prime mover efficiency is corrected according load and ambient conditions [13].

c Based on LHV equal to $47 \mathrm{MJ} / \mathrm{kg}$.

${ }^{\mathrm{d}}$ PER $=(W+Q) / m_{f} L H V$.

Table 3

Comparison between operating times (hours) in two rounds of simulations (C\#2, $\left.\left\{p_{i} \mid p_{i}=0.9995\right\}, T=8760 \mathrm{~h}\right)$.

\begin{tabular}{lllllll}
\hline Simulation \# & \multicolumn{2}{l}{ Round \#1 } & \multicolumn{3}{l}{ Round \#2 } \\
\cline { 2 - 7 } & $\begin{array}{l}\text { Total } \\
\text { time } t\end{array}$ & $\begin{array}{l}\text { Resilient } \\
\text { time } r\end{array}$ & $\begin{array}{l}\text { Normal } \\
\text { time } \\
(t-r)\end{array}$ & $\begin{array}{l}\text { Total } \\
\text { time } t\end{array}$ & $\begin{array}{l}\text { Resilient } \\
\text { time } r\end{array}$ & $\begin{array}{l}\text { Normal } \\
\text { time } \\
(t-r)\end{array}$ \\
\hline 1 & & & 3249 & 8760 & 7536 & 1224 \\
2 & 8760 & 5511 & 643 & 7772 & 6402 & 1370 \\
3 & 8760 & 8117 & 5760 & 4419 & 4341 \\
4 & 8760 & 5513 & 3247 & 8760 & 2537 \\
5 & 6213 & 5956 & 257 & 8760 & 6223 & 7 \\
6 & 8760 & 6402 & 2358 & 8760 & 8753 & 1550 \\
7 & 6416 & 5990 & 426 & 4757 & 3207 & 3603 \\
8 & 8760 & 1192 & 7568 & 8760 & 5157 & 1050 \\
9 & 7769 & 7163 & 606 & 8760 & 7710 & 5064 \\
10 & 8760 & 4278 & 4482 & 8760 & 3696 & 373 \\
\hline
\end{tabular}

\subsection{Resilient design framework: failure propagation simulations}

Because the simulation tool is based on a Monte Carlo approach, results are expected to vary for a given number of simulations for the same design concept. Table 3 shows sample results for two rounds of 10 simulations each for C\#2. For the first round, $\bar{r}=5436.3 \mathrm{~h}$ with a standard deviation $\sigma_{r}=2238.3 \mathrm{~h}$; the second round resulted in $\bar{r}=6485.1 \mathrm{~h}$ and $\sigma_{r}=1899.1 \mathrm{~h}$.

Table 4 shows the number of simulations affecting the results. ${ }^{2}$ "Normal simulations" is the number of simulations for which the plant never had a failed component; "failed simulations" is the number of simulations for which failed component(s) lead the plant to a complete loss of functionality (see Section 2.2); "resilient simulations" is the number of simulations for which failed component(s) did not lead the plant to a complete loss of functionality; and "average resilient time" is the average of the time $r$ for all simulations for which $t=T$ and $0<r \leqslant t$ (Eq. (3)).

${ }^{2}$ PC with Intel Core i7-2720QM @ $2.20 \mathrm{GHz}$ and 6 GB RAM took near $40 \mathrm{~h}$ to perform 100,000 simulations of C\#2.
Table 4

Results for different number of simulations (C\#2, $\left\{p_{i} \mid p_{i}=0.9995\right\}, T=8760 \mathrm{~h}$ ).

\begin{tabular}{|c|c|c|c|c|c|}
\hline 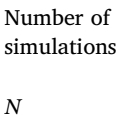 & $\begin{array}{l}\text { Normal } \\
\text { simulations }\end{array}$ & $\begin{array}{l}\text { Failed } \\
\text { simulations } \\
N_{f}\end{array}$ & $\begin{array}{l}\text { Resilient } \\
\text { simulations }\end{array}$ & $\begin{array}{l}\text { Average } \\
\text { resilient } \\
\text { time } \\
\bar{r}(h)\end{array}$ & $\begin{array}{l}\begin{array}{l}\text { Standard } \\
\text { deviation }\end{array} \\
\sigma_{r}(h)\end{array}$ \\
\hline 10 & 0 & 3 & 7 & 3805.4 & 1566.8 \\
\hline 20 & 0 & 6 & 14 & 4392.7 & 1020.6 \\
\hline 30 & 0 & 8 & 22 & 4904.9 & 744.8 \\
\hline 40 & 1 & 13 & 26 & 4252.0 & 1070.7 \\
\hline 50 & 0 & 13 & 37 & 4853.6 & 526.5 \\
\hline 60 & 3 & 21 & 36 & 3785.0 & 975.5 \\
\hline 70 & 2 & 25 & 48 & 4469.8 & 562.4 \\
\hline 80 & 0 & 31 & 49 & 4287.5 & 261.5 \\
\hline 90 & 2 & 31 & 57 & 4340.8 & 470.7 \\
\hline 100 & 2 & 35 & 63 & 4088.3 & 771.2 \\
\hline 200 & 6 & 68 & 126 & 4220.1 & 674.5 \\
\hline 300 & 5 & 96 & 199 & 4215.5 & 840.5 \\
\hline 400 & 4 & 128 & 268 & 4308.1 & 773.7 \\
\hline 500 & 14 & 160 & 326 & 4248.8 & 833.7 \\
\hline 1000 & 20 & 326 & 654 & 4171.9 & 773.8 \\
\hline 2000 & 40 & 648 & 1312 & 4284.5 & 712.0 \\
\hline 3000 & 56 & 983 & 1961 & 4244.7 & 744.8 \\
\hline 4000 & 74 & 1337 & 2589 & 4216.8 & 738.5 \\
\hline 5000 & 97 & 1670 & 3233 & 4212.5 & 727.9 \\
\hline 10,000 & 197 & 3277 & 6526 & 4239.0 & 740.4 \\
\hline 100,000 & 2005 & 32,429 & 65,566 & 4243.2 & 753.2 \\
\hline
\end{tabular}

The coefficient of variation (Eq. (7)) is a measure of dispersion and, as such, it is expected to converge to a certain value for an infinite number of simulations. The coefficient of variation of the average resilient time is plotted against the number of simulations in Fig. 9. It can be seen that for less than 100 simulations, the coefficient presents strong variation, but it tends to converge for more than 3000 simulations.

$c_{v, r}=\sigma_{r} / \bar{r}$

Consolidated results obtained from 3000 simulations for each concept are shown in Table 5. The probabilities are set as follows: $p_{i}=$ 0.9985 for pumps; $p_{i}=0.9990$ for heat exchangers (including cooling tower, radiators and HRSG) and $p_{i}=0.9995$ for all other component. 


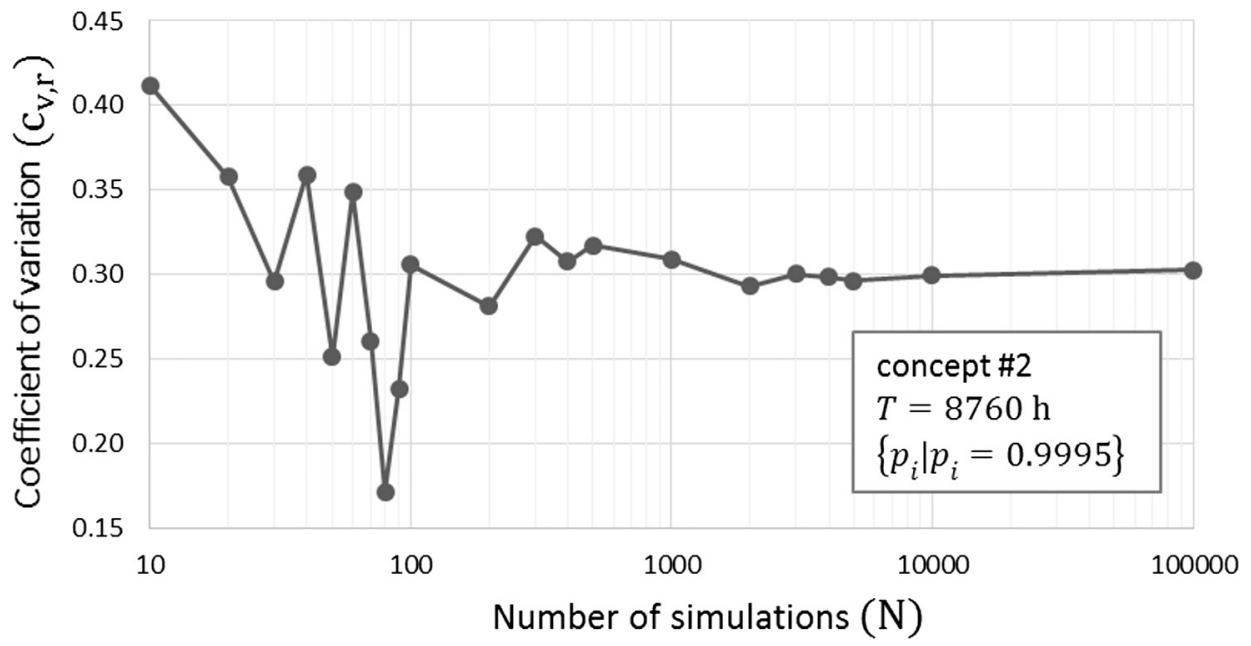

Fig. 9. Coefficient of variation of the average resilient time against number of simulations.

Table 5

Consolidated results for each concept: different probabilities $\left(\left\{p_{i} \mid 0.9985 \leqslant p_{i} \leqslant 0.9995\right\}, T=8760 \mathrm{~h}, N=3000\right)$.

\begin{tabular}{|c|c|c|c|c|c|c|c|c|c|c|c|}
\hline $\mathrm{C} \#$ & $N_{n}$ & $N_{f}$ & $N_{r}$ & $p_{f}\left(T,\left\{p_{i}\right\}\right)$ & $p_{r}\left(T,\left\{p_{i}\right\}\right)$ & $\bar{r}(\mathrm{~h})$ & $\sigma_{r}(\mathrm{~h})$ & $\bar{f}(\mathrm{~h})$ & $\sigma_{f}(\mathrm{~h})$ & $\bar{t}(\mathrm{~h})$ & $\rho\left(T,\left\{p_{i}\right\}\right)$ \\
\hline 1 & 1 & 1781 & 1218 & 0.594 & 0.406 & 2985 & 495 & 5113 & 2230 & 6595 & 0.753 \\
\hline 2 & 5 & 1345 & 1650 & 0.448 & 0.550 & 4082 & 688 & 5449 & 2293 & 7276 & 0.831 \\
\hline 3 & 1 & 1787 & 1212 & 0.596 & 0.404 & 2920 & 606 & 4913 & 1787 & 6468 & 0.738 \\
\hline 4 & 8 & 1467 & 1525 & 0.489 & 0.508 & 3659 & 761 & 5334 & 1467 & 7085 & 0.809 \\
\hline
\end{tabular}

Table 6

Consolidated results for each concept: equal probabilities $\left(\left\{p_{i} \mid p_{i}=0.9995\right\}, T=8760 \mathrm{~h}, N=3000\right)$.

\begin{tabular}{|c|c|c|c|c|c|c|c|c|c|c|c|}
\hline C\# & $N_{n}$ & $N_{f}$ & $N_{r}$ & $p_{f}\left(T,\left\{p_{i}\right\}\right)$ & $p_{r}\left(T,\left\{p_{i}\right\}\right)$ & $\bar{r}(\mathrm{~h})$ & $\sigma_{r}(\mathrm{~h})$ & $\bar{f}(\mathrm{~h})$ & $\sigma_{f}(\mathrm{~h})$ & $\bar{t}(\mathrm{~h})$ & $\rho\left(T,\left\{p_{i}\right\}\right)$ \\
\hline 1 & 69 & 1384 & 1547 & 0.461 & 0.516 & 3188 & 1080 & 5057 & 2289 & 7053 & 0.805 \\
\hline 2 & 56 & 983 & 1961 & 0.328 & 0.654 & 4245 & 1275 & 5198 & 2330 & 7594 & 0.867 \\
\hline 3 & 56 & 1577 & 1367 & 0.526 & 0.456 & 2890 & 889 & 4849 & 2319 & 6705 & 0.765 \\
\hline 4 & 56 & 1241 & 1703 & 0.414 & 0.568 & 3619 & 1121 & 5116 & 2373 & 7254 & 0.828 \\
\hline
\end{tabular}

As previously pointed out in Section 2.2, our proposed ideal failure propagation mechanism requires the components having the same set of probabilities $\left\{p_{i}\right\}$ to keep the simulations unbiased and, most important, to make sure that the concepts differ only in their configuration. However, having actual, reliable values of these probabilities is quite difficult during the conceptual design phase. Therefore, we examine here whether it is possible to consider a simplification where all $p_{i}$ are equal, so that the difficulty of supplying actual $p_{i}$ is avoided. We will argue later in the discussion that such simplification are not only convenient but also do not appear to compromise the resilience analysis. Results obtained for each concept considering equal probabilities $\left\{p_{i}=0.9995\right\}$ are shown in Table 6 .

\subsection{Baseline results from analytical methodology}

Overcoming the disadvantages of the stochastic nature of Monte Carlo-based approaches with a deterministic approach would seem like a desirable alternative. To that end, results from an analytical methodology reported in the literature [6] based on complex network theory are presented in this section for comparison. The analytical methodology aims to assess the resilience of complex engineering systems that can be represented as networks, and it was applied here to the cogeneration design concepts presented in Section 2.1. The metrics for resilience and the method how to compute them are based on the work of Mehrpouyan et al. [6] and are briefly summarized here:
A plant physical model is represented as a graph (components correspond to vertices; connections correspond to edges) and three square matrices related to the graph: adjacency matrix $A=\left[a_{i j}\right]$, degree matrix $D=\left[d_{i j}\right]$ and Laplacian matrix $L=\left[\ell_{i j}\right]$. Adjacency matrix $A$ represents the design connection between two components. If a component $i$ is connected to a component $j$, then $a_{i j}=1$; otherwise, $a_{i j}=0$. If $i$ is connected to $j$, then $j$ is connected to $i$, so that $a_{i j}=a_{j i}=1$. Since a component cannot be connected to itself, $a_{i j}=0$ for $i=j$. Degree matrix represents the number of connections a component $i$ has. For $i=j, d_{i i}=d_{j j}$ is the number of entries equal to 1 in line $i$ (or row $j$ ) of adjacency matrix. For $i \neq j, d_{i j}=0$. The average node degree for a plant with $k$ components is given in Eq. (7). Laplacian matrix is defined as $L=D-A$ (Eq. (8)).

$\bar{d}=\left(\frac{1}{k}\right) \sum_{i=1}^{k} d_{i i}$

$\left[\ell_{i j}\right]=\left[d_{i j}\right]-\left[a_{i j}\right]$

Three resilient metrics are obtained from those matrices: algebraic connectivity, spectral radius and modularity. Algebraic connectivity describes the difficulty to isolate a component from the rest of the system [6] and it is calculated as the second smallest eigenvalue of $L$. Spectral radius is calculated as the highest eigenvalue of $A$. A smaller spectral radius results in higher system resilience when compared to other systems of similar size, i.e., a similar average node degree of the 
Table 7

Analytical methodology results for each concept.

\begin{tabular}{llllllll}
\hline $\mathrm{C \#}$ & $k$ & $\min \left(d_{i i}\right)$ & $\max \left(d_{i i}\right)$ & $\bar{d}$ & $\begin{array}{l}\text { Algebraic } \\
\text { connectivity }\end{array}$ & $\begin{array}{l}\text { Spectral } \\
\text { radius }\end{array}$ & Modules \\
\hline 1 & 22 & 1 & 15 & 4.45 & 0.710 & 6.16 & 6 \\
2 & 28 & 1 & 19 & 4.93 & 0.804 & 6.62 & 7 \\
3 & 20 & 1 & 12 & 4.00 & 0.467 & 5.62 & 7 \\
4 & 23 & 1 & 13 & 4.17 & 0.697 & 5.78 & 8 \\
\hline
\end{tabular}

graph [6]. The spectral radius does not have a defined range of values and it is not useful per se, i.e., it is only a comparative parameter between systems of similar size. Complex network theory defines modules as densely connected node (or component) groups. Sarkar et al. [29] formalized a method to compute the number of modules in complex engineering systems by graphically comparing the indexed spectrum of the adjacency matrix to the spectrum of a random graph of the same size. If the two correspond, there is no modularity. Otherwise, there will be a large gap between the $k$-th and $(k+1)$-th eigenvalues. This $k$ (or $k+1$ ) is retained as the number of modules in the system.

The computed adjacency, degree and Laplacian matrices for design concept C\# 1 are shown in the Appendix as are the eigenvalues $\lambda_{\ell, i}$ from Laplacian matrices and eigenvalues $\lambda_{a, i}$ from adjacency matrices together with the random graph indexed spectrum corresponding to the respective design concept. The main results from the analytical methodology are summarized in Table 7 which shows that the different metrics are not consistent across different design concepts, making a design choice based on the analytical method difficult. Possible explanations for discrepancy regarding the analytical metrics are: (i) spectral radius could not be fully used to compare all concepts, which is a severe limitation when resilience evaluation of systems with different sizes is required; (ii) modularity determination is somewhat depending on visual interpretation of the spectra, bringing some subjectivity to the resilience analysis. However, a more general explanation is that all these metrics were derived for homogeneous networks (e. g., computer networks or power networks, such as those studied by Mehrpouyan et al. [6]). Cogeneration plants, on the other hand, are heterogeneous networks. Connections between the components in cogeneration plants involve both energy and mass flow. Because connections are of different type, alternative paths are much more restricted. Besides being different from each other (water, exhaust gases, power etc.), some flows occur in specific directions only. For example, exhaust gases from a gas turbine flows towards the heat recovering steam generator (HRSG), but it is not allowed to flow in the opposite direction. Although there are mutual connections, for example, turbine and HRSG, the former could work without the latter, but not the other way round. Thus, a cogeneration plant should be represented as a directed graph, which would result in non-symmetric adjacency matrix and complex eigenvalues.

\section{Discussion}

\subsection{Simulation tool results}

Referring back to Table 5, all metrics derived from the resilient design framework simulations show that the most resilient is concept

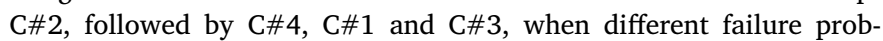
abilities $p_{i}$ (as one might encounter them in actual plants) are attributed to the components. However, having such information in early design stages is difficult. It turns out that the simplification of considering only equal failure probabilities $p_{i}$ attributed for all components - while changing the magnitude of the metrics - does not change the order. We assert without formal proof that this is true for situations where high reliability components are used (i.e., $p_{i}$ is large) and where the difference between $p_{i}$ is within an order of magnitude because the relative difference between component $p_{i}$ washes out when considered in the context of complex system reliability. Further examination of this point will be studied in ongoing work. A comparison of both approaches is summarized in Table 8.

As seen in Table 8 , the set of failure probabilities $\left\{p_{i}\right\}$ does not change the order of resilience, provided that the same set of probabilities is considered for all concepts. Recall that this is the first assumption in the ideal failure propagation mechanism presented in Section 2.2. This set can be interpreted as establishing a common reference frame from which the resilience of different designs can be compared. Results presented in Table 8 evinces that the proposed design framework defines resilience as an intrinsic property of the plant configuration (where configuration is the way the components of a plant are placed and connected).

As expected, a configuration with low $p_{i}$ components is more prone to fail than the same configuration with high $p_{i}$ components (as supported by the metrics in Table 8). Without assessing other design options, that information alone would not be helpful in guiding the design team towards finding a more resilient configuration. However, the simulation tool allows the design team to compare the resilience of any configuration in early design phases even when detailed information of the components (such as $p_{i}$ ) is not available. As pointed out before, the impact of modifications in the plant configuration on the resilience can be evaluated with the simulation tool in the absence of precise component failure information.

Design concept C\#2 is the most resilient because it has the highest probability to engage in resilient operation (highest $p_{r}$ ) and to withstand in resilient operation for the longest time (highest $\bar{r}$ ). Design concept $\mathrm{C \# 2}$ also has the configuration less prone to completely fail (lowest $p_{f}$ ), but even when that happens, it is the one that operates for the longest time (highest $\bar{f}$ ). Overall, design concept $\mathrm{C} \# 2$ is expected to operate for the longest time on average (highest $\bar{t}$ ). The fact that design concept $\mathrm{C} \# 2$ has the highest $\bar{t}$ means that it presents the highest

Table 8

Resilience metrics comparison: different $\mathrm{p}_{\mathrm{i}}$ vs equal $\mathrm{p}_{\mathrm{i}}$

\begin{tabular}{|c|c|c|c|c|c|}
\hline Case & Resilience metric & Most resilient design & $\rightarrow$ & $\rightarrow$ & Least resilient design \\
\hline Different $p_{i}$ & Average resilient time (h) & C\#2 (4082.1) & C\#4 (3658.5) & C\#1 (2985.3) & C\#3 (2919.7) \\
\hline$T=8760 \mathrm{~h}$ & Average time until failure $(\mathrm{h})$ & C\#2 (5449.0) & C\#4 (5334.0) & C\#1 (5113.0) & C\#3 (4913.0) \\
\hline Pumps: $p_{i}=0.9985$ & Average operating time $(\mathrm{h})$ & C\#2 (4832.6) & C\#4 (4476.4) & C\#1 (3559.5) & C\#3 (3542.0) \\
\hline Heat ex: $p_{i}=0.9990$ & Prob. of resilient operation & C\#2 (0.550) & C\#4 (0.508) & C\#1 (0.406) & C\#3 (0.404) \\
\hline \multirow{2}{*}{ Other: $p_{i}=0.9995$} & Prob. of failing & C\#2 (0.448) & C\#4 (0.489) & C\#1 (0.594) & C\#3 (0.596) \\
\hline & Normalized resilience index & C\#2 (0.552) & C\#4 (0.511) & C\#1 (0.406) & C\#3 (0.404) \\
\hline Equal $p_{i}$ & Average resilient time (h) & C\#2 (4245.7) & C\#4 (3658.5) & C\#1 (3187.5) & C\#3 (2889.5) \\
\hline$T=8760 \mathrm{~h}$ & Average time until failure $(\mathrm{h})$ & C\#2 (5197.6) & C\#4 (5116.0) & C\#1 (5056.7) & C\#3 (4848.6) \\
\hline \multirow[t]{4}{*}{$p_{i}=0.9995$} & Average operating time $(\mathrm{h})$ & C\#2 (7592.7) & C\#4 (7252.6) & C\#1 (7051.6) & C\#3 (6703.9) \\
\hline & Prob. of resilient operation & C\#2 (0.654) & C\#4 (0.568) & C\#1 (0.516) & C\#3 (0.456) \\
\hline & Prob. of failing & $\mathrm{C \# 2}(0.328)$ & C\#4 (0.414) & C\#1 (0.461) & C\#3 (0.526) \\
\hline & Normalized resilience index & $\mathrm{C \# 2}(0.867)$ & C\#4 (0.828) & C\#1 (0.805) & C\#3 (0.765) \\
\hline
\end{tabular}


Table 9

Resilience index comparison: different $\mathrm{p}_{\mathrm{i}}$ vs equal $\mathrm{p}_{\mathrm{i}}$

\begin{tabular}{lllll}
\hline Case & C\# & Lower limit & Resilience index & Upper limit \\
\hline Different $p_{i}$ & 2 & 0.622 & 0.831 & 1 \\
$T=8760 \mathrm{~h}$ & 4 & 0.609 & 0.809 & 1 \\
Pumps: $p_{i}=0.9985$ & 1 & 0.584 & 0.753 & 1 \\
Heat ex: $p_{i}=0.9990$ & 3 & 0.561 & 0.738 & 1 \\
Other: $p_{i}=0.9995$ & & & & \\
Same $p_{i}$ & 2 & 0.593 & 0.867 & 1 \\
$T=8760 \mathrm{~h}$ & 4 & 0.584 & 0.828 & 1 \\
$p_{i}=0.9995$ & 1 & 0.577 & 0.805 & 1 \\
& 3 & 0.533 & 0.765 & 1
\end{tabular}

resilient index, since $\rho$ is a normalization of $\bar{t}$ through $T$. The resilient index is a convenient way to provide an assessment for resilience, in the same way efficiency is used to assess the energy conversion in energy systems. Note that the limit case $p_{f}=0$ in Eq. (6) defines the upper limit $\rho \leqslant 1$ regardless of $\bar{f}$. Due to the stochastic nature of the simulations, on the other hand, it is not possible to anticipate the value of $\bar{f}$ when $p_{f}=1$. Assuming that $\bar{f}$ remains the same, one could define $\bar{f} / T \lesssim \rho$ from Eq. (6) as a reference lower limit for $p_{f}=1$. Thus, for all concepts with the same $T$ and $\left\{p_{i}\right\}$, the most resilient design possible would have $\rho=1$ and the least resilient design possible would have $\rho \cong \bar{f} / T$. Table 9 shows the resilient index and respective limits of all concepts for both equal $p_{i}$ and different $p_{i}$ cases.

For the particular sets of $p_{i}$ considered, design concept C\#3 is the least affected by components with low $p_{i}$, since its resilient index decreased $2.32 \%$. Design concept C\#1 shows the highest decrease in its resilience index $(6.48 \%)$ and it is the most affect by components with low $p_{i}$. Table 8 shows how other metrics differ when considering equal $p_{i}$ and different $p_{i}$ cases. As expected, the overall probability of failing $p_{f}$ increases for the different $p_{i}$ case because $p_{i}$ decreased for some of the components (relative to the case with equal $p_{i}$ ). The probability of resilient operation $p_{r}$ decreased in the different $p_{i}$ case. In both cases, the number of non-failed simulations $N_{n}$ is much smaller than the number of failed $\left(N_{f}\right)$ and resilient $\left(N_{r}\right)$ simulations, so that $N=N_{n}+N_{f}+N_{r}$ can be approximated as $N \cong N_{f}+N_{r}$. Since $N$ is the same in both cases and $N_{f}$ increased in the different $p_{i}$ case, if follows that $N_{r}$, and consequently $p_{r}$, must decrease. The resilient operating time is affected by $p_{r}$ (Eq. (2)), so that $\bar{r}$ also decreases in the different $p_{i}$ case. The time until failure $\bar{f}$ in the different $p_{i}$ case increases because the lower $p_{i}$ components tend to fail earlier, on average, in the completely failed simulations, so the plant has to live with the failure for longer time until complete failure. Indeed, taking design concept C\#1 as example, a failure first appears after $1038 \mathrm{~h}$ in the different $p_{i}$ case, but it appears after $1529 \mathrm{~h}$ in the equal $p_{i}$ case. The combined increase of $p_{f}$ and $\bar{f}$ in the different $p_{i}$ case results ultimately in decreasing $\bar{t}$ and $\rho$.

The comparison between the results from simulation tool with the ones from analytical methodology found in [6] shows that the latter presented discrepancies. It is shown in Table 10 that none of the analytical metrics agree to point out the most resilient design (or the least resilient one, for that matter). On the other hand, metrics obtained by simulation results from our proposed method are consistent across all design alternatives. In addition, unlike computations for the spectral radius, our simulation tool does not require that plants have the same size. The simulation tool also confirms that plants with redundant prime movers are more resilient than the respective ones with only one prime mover (i.e., C\#2 is more resilient than $\mathrm{C \# 1}$ and $\mathrm{C \# 4}$ is more

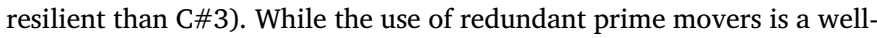
known engineering practice to maximize functionality, it is something that the analytical metrics failed to capture in the cases presented here. The number of connections also plays an important role in resilience, since among plants with the same number of prime movers, those with more connections are more resilient (i.e., C\#2 is more resilient than C\#4 and C\#1 is more resilient than C\#3). While this, too, is not a new insight, our tool allows the assessment of the impact, perhaps even visà-vis redundant design solutions.

It should be noted that the design team's choice between several available design alternatives also depends on the criticality of the application. As an example, resilience is more desirable than efficiency in an oil rig cogeneration plant. If the prime mover fails in this case, it is not possible to count on an external grid to provide power while mover functionality is restored. Thus, fault handling (or resilient) strategies in the context of the Heimes definition of resilience should be considered, as briefly discussed next.

\subsection{Fault handling strategies}

Although it is not intended to examine fault handling strategies here in depth, it may nonetheless be worth to mention some aspects of that in the context of cogeneration plants, which, we believe, can be extended to any kind of complex engineering systems.

Perhaps the most typical strategy to avoid failure within a system is to employ direct redundancy. In cogeneration, engineering practices such as having more than one prime mover and operation parallel with the grid are redundancies typically considered to assure power delivery. When chilled water is required, it is also common to have a mechanical driven chiller as backup. Redundancy is a strategy adopted during the design phase, because it ultimately affects the plant configuration. Results from simulations in the previous section quantify the degree to which plants with redundant prime movers are more resilient.

Another common practice in cogeneration is power load prioritization, i.e., a determination which loads or class of loads should remain fed in case of failure. Load prioritization is a fault management strategy that seeks to minimize the impact of a fault. For example, while power delivery is not fully restored in a hospital, intensive care units and operating rooms must keep working, but laundry and cafeteria may not. Unlike redundancy, load prioritization is not a strategy related to the system configuration, but it should definitely be considered during design phase. This strategy can be also extended to other types of load, such as chilled water. Irrespective of the load, prioritization is a clear way to set "acceptable degradation parameters", according to Heimes' definition, for cogeneration plants.

Table 10

Resilience metrics comparison: simulation vs analytical methodology.

\begin{tabular}{|c|c|c|c|c|c|}
\hline Resilience metric & & Most resilient design & $\rightarrow$ & $\rightarrow$ & Least resilient design \\
\hline \multirow[t]{3}{*}{ Analytical methodology [6] } & Algebraic connectivity & C\#2 (0.804) & C\#1 (0.710) & C\#4 (0.697) & C\#3 (0.467) \\
\hline & Spectral radius & C\#3 (5.62) & C\#4 (5.78) & C\#1 (6.16) & - \\
\hline & Modularity & C\#4 (8) & $\mathrm{C \# 2}$ and $\mathrm{C \# 3}$ (7) & & C\#1 (6) \\
\hline Simulations & Average resilient time $(\mathrm{h})$ & C\#2 (4245.7) & C\#4 (3658.5) & C\#1 (3187.5) & C\#3 (2889.5) \\
\hline$T=8760 \mathrm{~h}$ & Average time until failure $(\mathrm{h})$ & C\#2 (5197.6) & C\#4 (5116.0) & C\#1 (5056.7) & C\#3 (4848.6) \\
\hline \multirow[t]{4}{*}{$p_{i}=0.9995$} & Average operating time $(\mathrm{h})$ & C\#2 (7592.7) & C\#4 (7252.6) & C\#1 (7051.6) & $\mathrm{C \# 3}(6703.9)$ \\
\hline & Probability of resilient operation & C\#2 (0.654) & C\#4 (0.568) & $\mathrm{C \# 1}(0.516)$ & C\#3 (0.456) \\
\hline & Probability of failing & C\#2 (0.328) & C\#4 (0.414) & C\#1 (0.461) & C\#3 (0.526) \\
\hline & Normalized resilience index & C\#2 (0.867) & C\#4 (0.828) & C\#1 (0.805) & C\#3 (0.765) \\
\hline
\end{tabular}




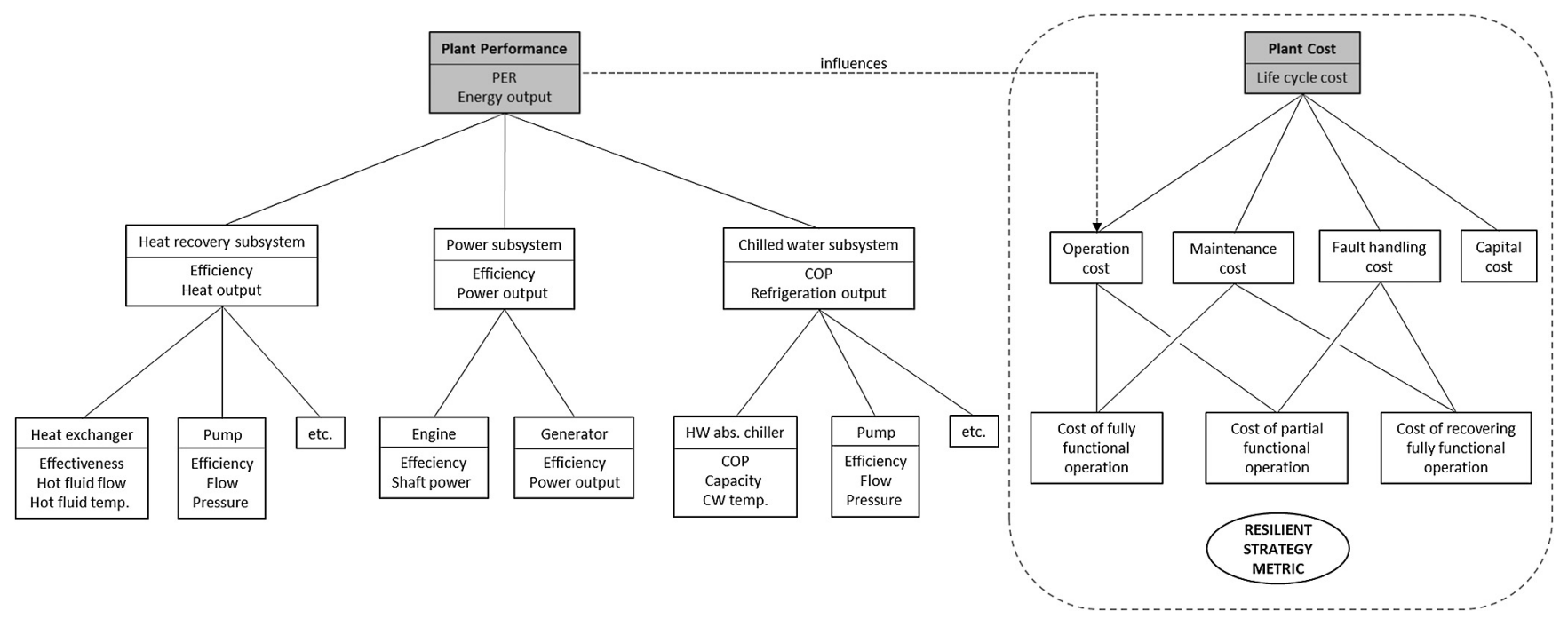

Fig. 10. Life cycle cost as a resilient metric for fault handling strategies.

The previous strategies are technical, but management-related ones also play an important role on resilience. For example, keeping spare parts, well trained maintenance team for quick repair, and specialized outsourced services under contract is a strategy to recover full functionality "within an acceptable time", which is in accordance with the second part of Heimes' definition [9]. It is interesting to note that management-strategies can be related to technical ones. For example, design concepts with long enough average resilient time can minimize the need to have spare parts, because it would allow for time to acquire the part instead of keeping it in stock. The use of a resilient strategy depends on the application and it is expected to differ considerably between, say, a hotel cogeneration plant connected to the grid for power and hot water and a plant for power and superheated steam in an oil rig.

Regardless of the strategy nature, a metric to determine whether resilient strategies are appropriate or not is desired. It is quite unlikely that a system does not have any kind of failure over its lifetime. Either fixing the failure or accepting loss of performance or full functionality for not fixing it has an associated cost. In this context (again, related to the second part of Heimes' definition), plant life cycle cost (LCC) seems to be a natural metric to choose the resilient strategy (the one with lowest LCC should be adopted). Moreover, resilience indirectly becomes a high level design requirement itself, since it is incorporated into LCC (Fig. 10). Some difficulties to calculate the plant LCC during the design phase taking into account fault handling costs are: (i) to predict failure occurrence; (ii) to predict for how long the plant withstand degraded operation due to the failure; (iii) to predict the performance of the plant under degraded conditions. We believe the simulation tool presented in this work could help to overcome the first two limitations; the latter could be approached through thermodynamic modelling by considering the degraded performance as an off-design condition.

\subsection{Limitations and further developments}

The resilient design framework and respective simulation tool introduced in Section 2.2 can be used to derive metrics for resilience by considering the actual configuration of the system. Explicit knowledge regarding connections between components and redundancies are required, as illustrated by the roles that the attributes [affectedBy] and [redundancies], respectively, play on the failure propagation (Figs. 7 and 8). As is the case with many Monte Carlo simulations, they can demand considerable computing time. This is sufficient motivation to investigate time-independent metrics. On the other hand, we believe the resilient design framework can be adapted for any complex engineering system, because none of the attributes of the object [component] are related to the nature or function of the component. Another area of improvement is the consideration of health monitoring components in the design concept as well as the remediation of faults through repair action. Folding these elements into the simulation tool would allow a more precise assessment of life-cycle cost and provide a holistic evaluation of the plant operations over its entire life (possibly several decades).

\section{Conclusion}

We postulate that resilience is an intrinsic property of a plant configuration (configuration being the way the components of a plant are placed and connected). This paper explored the resilience of the conceptual design of natural gas-fueled cogeneration plants. To that end, we developed a novel resilient design framework based on an ideal failure propagation mechanism that is exercised via the Monte Carlo approach, from which we propose new metrics to assess the resilience of cogeneration plants during the conceptual design phase. The design framework is embedded in a stochastic simulation tool of failure propagation within a cogeneration plant. Although the framework is based on several idealizations, the simulation tool is particularly useful in practice because resilience can be evaluated in early design phases even if there is not much detailed information (especially failure probabilities) about system components available at this point. Moreover, if such probabilities are available, the simulation tool can incorporate these and provide a more refined evaluation. The comparison of simulations for two different sets of probabilities (one with idealized equal probabilities; the other with individualized probabilities) showed that the resilience ranking remained consistent across the different design concepts.

Resilience metrics corroborate that plants with redundant prime movers are more resilient than the plants with only one prime mover. Although having redundant prime movers is a very well-known engineering practice to maximize functionality, the number of connections also plays an important role in resilience, since among plants with the same number of prime movers, those with more connections are more resilient. This is an interesting insight for the design team, because increasing the number of connections can be more cost-effective than having redundancies and the simulation tool can be used to test different alternatives. Results from an analytical methodology found in the literature were obtained and compared to those from the simulation tool but results using that methodology exhibited discrepancies in the metrics, so that no easy conclusion could be drawn about the most resilient cogeneration plant. 
Based solely on thermodynamic aspects, design teams would choose concept $\mathrm{C \# 1}$. On the other hand, when resilience is considered, simulations shows that concept $\mathrm{C \# 2}$ is the most resilient because: (i) it has the highest probability to engage resilient operation; (ii) it withstands resilient operation for the longest time; (iii) it has the configuration less prone to completely fail; (iv) it operates for the longest time until complete failure; (v) on average, it is expect to operate for the longest period. Thus, the design team has more information to make a proper decision during the design phase while also factoring in the criticality of the application. Results from resilience analysis are also useful as guidelines to establish fault handling (or resilient) strategies during the design phase. The life-cycle cost would be an appropriate metric to decide which fault handling strategy should be adopted and the simulation tool presented here can be expanded to integrate that metric.

\section{Acknowledgements}

To Prof. Andy Dong, from California College of the Arts, for providing advice on the role modules in complex engineering systems.

To FAPESP - São Paulo Research Foundation, for sponsoring the postdoc internship of the first author at NASA Ames Research Center (Proc. 2016/19255-7).

\section{Appendix A}

Adjacency matrix, degree matrix and Laplacian matrix for design concept C\#1 are shown in Fig. 11. For each design concept, eigenvalues $\lambda_{\ell, \mathrm{i}}$ from Laplacian matrices and eigenvalues $\lambda_{\mathrm{a}, \mathrm{i}}$ from adjacency matrices are shown in Table 11. The eigenvalues are arranged in descending order in order to visually show the indexed spectrum plot for each design concept in Fig. 12. Fig. 12 also shows the random graph indexed spectrum corresponding to the respective design concept.

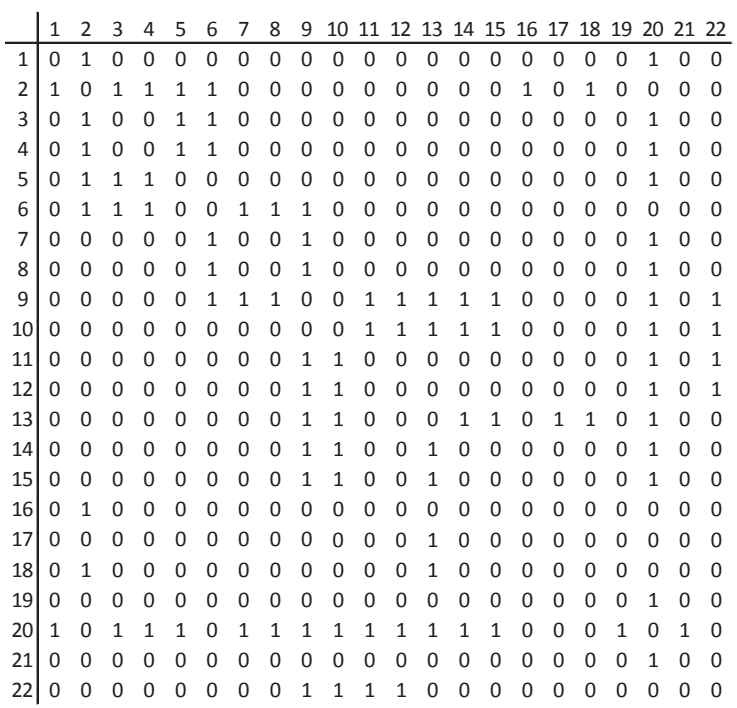

(a) Adjacency matrix

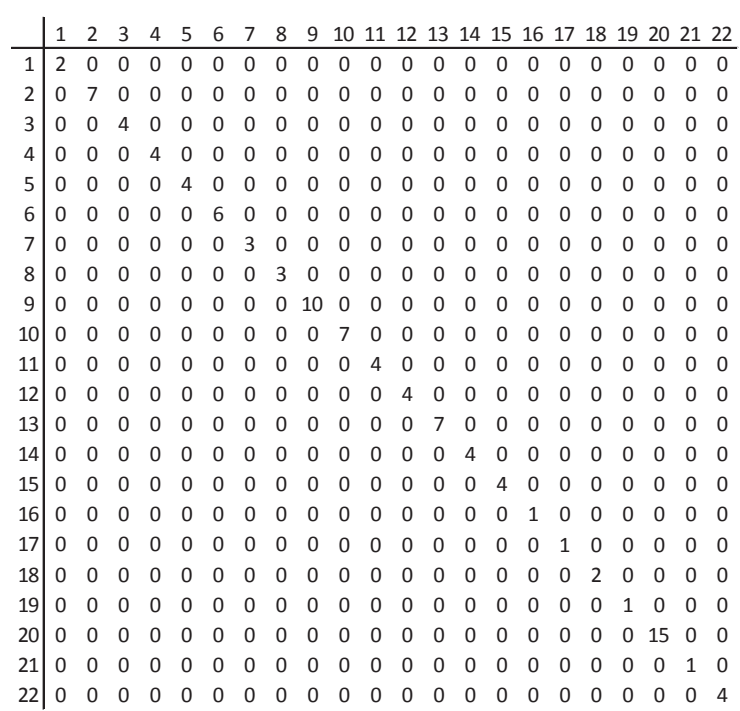

\section{(b) Degree matrix}

Nomenclature

1. Generator (G)

2. Engine (G)

3. Engine pump (EP1)

4. Engine pump (EP2)

5. Radiator (R)

6. Heat exchanger (HEX)

7. Abs. chiller pump (ACP1)

8. Abs. chiller pump (ACP2)

9. Hot water abs. chiller (HWAC)

10. Mech.-driven chiller (MDC)

11. Chilled water pump (CWP1)
12. Chilled water pump (CWP2)

13. Cooling tower (CT)

14. Cooling tower pump (CTP1)

15. Cooling tower pump (CTP2)

16. gas line (g)

17. water line $(w)$

18. environment (e)

19. GRID

20. BUS

21. Power load (PWL)

22. Chilled water load (CWL)

$19\left(\begin{array}{cccccccccccccccccccccc}0 & 0 & 0 & 0 & 0 & 0 & 0 & 0 & 0 & 0 & 0 & 0 & 0 & 0 & 0 & 0 & 0 & 0 & 1 & -1 & 0 & 0\end{array}\right.$

$21 \mid \begin{array}{rlllllllllllllllllllll}0 & 0 & 0 & 0 & 0 & 0 & 0 & 0 & 0 & 0 & 0 & 0 & 0 & 0 & 0 & 0 & 0 & 0 & 0 & -1 & 1 & 0\end{array}$

$22 \mid \begin{array}{llllllllllllllllllllll}0 & 0 & 0 & 0 & 0 & 0 & 0 & 0 & -1 & -1 & -1 & -1 & 0 & 0 & 0 & 0 & 0 & 0 & 0 & 0 & 0 & 4\end{array}$

\section{(c) Laplacian matrix}

Fig. 11. Adjacency, degree and Laplacian matrices for C\#1. 
Table 11

Eigen values from Laplacian and adjacency matrices for each concept.

\begin{tabular}{|c|c|c|c|c|c|c|c|c|}
\hline \multirow[t]{2}{*}{$\mathrm{i}$} & \multicolumn{4}{|l|}{$\lambda_{\ell, \mathrm{i}}$} & \multicolumn{4}{|l|}{$\lambda_{\mathrm{a}, \mathrm{i}}$} \\
\hline & $\mathrm{C \# 1}$ & $\mathrm{C \# 2}$ & $\mathrm{C} \# 3$ & $\mathrm{C} \# 4$ & $\mathrm{C} \# 1$ & $\mathrm{C} \# 2$ & C\#3 & $\mathrm{C \# 4}$ \\
\hline 1 & 16.0990 & 20.1000 & 13.1359 & 14.1700 & 6.1591 & 6.6202 & 5.6200 & 5.7769 \\
\hline 2 & 11.2824 & 12.2228 & 10.9340 & 11.3291 & 3.5435 & 3.8515 & 2.4230 & 2.8896 \\
\hline 3 & 8.3501 & 8.8039 & 7.8044 & 7.8845 & 1.9621 & 3.3234 & 1.7624 & 1.8825 \\
\hline 4 & 7.9784 & 8.0990 & 7.0637 & 7.2394 & 1.6250 & 2.6182 & 1.6345 & 1.7624 \\
\hline 5 & 7.5423 & 8.0183 & 6.0158 & 6.6416 & 1.3611 & 1.6513 & 1.3517 & 1.4546 \\
\hline 6 & 6.9638 & 7.7999 & 4.8342 & 5.4605 & 0.5709 & 1.6033 & 0.8219 & 1.4142 \\
\hline 7 & 5.3277 & 7.3437 & 4.0000 & 4.9557 & 0.1962 & 0.7068 & 0.2789 & 1.0307 \\
\hline 8 & 4.9463 & 6.8832 & 4.0000 & 4.6185 & 0.0000 & 0.3579 & 0.0000 & 0.3030 \\
\hline 9 & 4.0000 & 6.2181 & 3.5952 & 4.0937 & 0.0000 & 0.1947 & 0.0000 & 0.0000 \\
\hline 10 & 4.0000 & 5.4113 & 3.0000 & 4.0000 & 0.0000 & 0.1050 & 0.0000 & 0.0000 \\
\hline 11 & 4.0000 & 5.3376 & 2.6151 & 4.0000 & 0.0000 & 0.0000 & 0.0000 & 0.0000 \\
\hline 12 & 3.1424 & 4.3234 & 2.0055 & 4.0000 & 0.0000 & 0.0000 & 0.0000 & 0.0000 \\
\hline 13 & 3.0000 & 4.0000 & 1.6796 & 3.2391 & 0.0000 & 0.0000 & 0.0000 & 0.0000 \\
\hline 14 & 2.5384 & 4.0000 & 1.5535 & 2.8799 & 0.0000 & 0.0000 & -0.7607 & 0.0000 \\
\hline 15 & 1.9865 & 4.0000 & 1.3261 & 2.4504 & -0.4155 & 0.0000 & -1.0789 & 0.0000 \\
\hline 16 & 1.8010 & 4.0000 & 1.0000 & 1.9154 & -0.7962 & 0.0000 & -1.3383 & -1.0401 \\
\hline 17 & 1.4585 & 4.0000 & 0.9012 & 1.8159 & -1.2663 & 0.0000 & -1.8494 & -1.0942 \\
\hline 18 & 1.0476 & 3.0841 & 0.6084 & 1.3941 & -1.6793 & 0.0000 & -2.1291 & -1.3817 \\
\hline 19 & 1.0000 & 2.7409 & 0.4673 & 1.3004 & -1.9659 & -0.6710 & -3.2858 & -1.4142 \\
\hline 20 & 0.8261 & 2.1960 & 0.0000 & 1.0000 & -2.4506 & -0.8447 & -3.4501 & -1.9519 \\
\hline 21 & 0.7095 & 2.0011 & & 0.9153 & -3.0471 & -1.3845 & & -2.2895 \\
\hline 22 & 0.0000 & 1.9437 & & 0.6966 & -3.7970 & -1.6813 & & -3.3856 \\
\hline 23 & & 1.4912 & & 0.0000 & & -1.7042 & & -3.9567 \\
\hline 24 & & 1.2323 & & & & -2.0000 & & \\
\hline 25 & & 1.0000 & & & & -2.3894 & & \\
\hline 26 & & 0.9454 & & & & -2.8066 & & \\
\hline 27 & & 0.8039 & & & & -3.2462 & & \\
\hline 28 & & 0.0000 & & & & -4.3044 & & \\
\hline
\end{tabular}
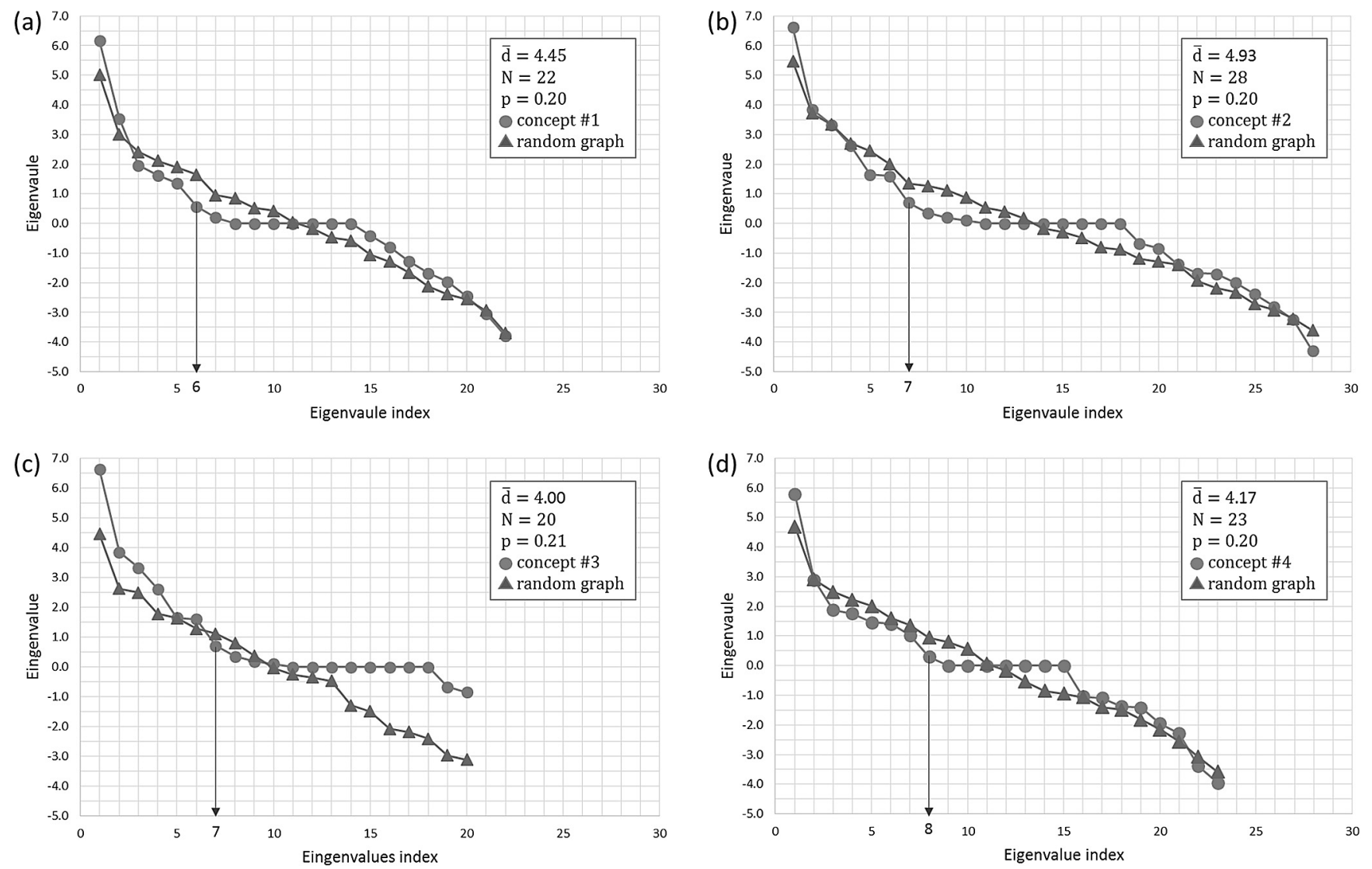

Fig. 12. Index spectrum of all concepts (lines for visualization purposes only). 


\section{References}

[1] Choudhury A, Chandra H, Arora A. Application of solid oxide fuel cell technology for power generation - a review. Renew Sustain Energy Rev 2013;20:430-42.

[2] Chen W, Wu P, Lin Y. Performance optimization of thermoelectric generators designed by multi-objective genetic algorithm. Appl Energy 2018;209:211-23.

[3] Di Somma M, Yan B, Bianco N, Graditi G, Luh PB, Mongibello L, et al. Multi-objective design optimization of distributed energy systems through cost and exergy assessments. Appl Energy 2017;204:1299-316.

[4] Yin Q, Du W, Cheng L. Optimization design of heat recovery systems on rotary kilns using genetic algorithms. Appl Energy 2017;202:153-68.

[5] Ganjehkaviri A, Mohd Jaafar MN, Hosseini SE, Barzegaravval H. On the optimization of energy systems: results utilization in the design process. Appl Energy 2016;178:587-99.

[6] Mehrpouyan H, Haley B, Dong A, Tumer IY, Hoyle C. Resilience analysis for complex engineered system design. Artif Intell Eng Des Anal Manuf 2015;29(01):93-108

[7] Postnikov I, Stennikov V, Mednikova E, Penkovskii A. Methodology for optimization of component reliability of heat supply systems. Appl Energy, in press, corrected proof. 10.1016/j.apenergy.2017.11.073.

[8] Yodo N, Wang P. Engineering resilience quantification and system design implications: a literature survey. J Mech Des 2016;138(11):1-13.

[9] Heimes YY. On the definition of resilience in systems. Risk Anal 2009;29(04):498-501.

[10] Matelli JA, Silva JC, Bazzo E. An expert system prototype for designing natural gas cogeneration plants. Expert Syst Appl 2009;36(4):8375-84.

[11] Matelli JA, Bazzo E, Silva JC. Development of a case-based reasoning prototype for cogeneration plant design. Appl Energy 2011;88(9):3030-41.

[12] Matelli JA, Silva JC, Bazzo E. Cogeneration design problem: Computational complexity analysis and solution through an expert system. Eng Comput. 2014;31(6):1034-51.

[13] Silva JC, Matelli JA, Bazzo E. Development of a knowledge-based system for cogeneration plant design: verification, validation and lessons learned. Knowl-Based Syst 2014;67:230-43.

[14] Matelli JA. Conceptual design of biomass-fired cogeneration plant through a knowledge-based system. J Braz Soc Mech Sci Eng 2016;38(2):535-49.

[15] Bejan A, Tsatsaronis G, Moran M. Thermal Design and Optimization. New York: John Wiley and Sons; 1996.

[16] Stoecker WF. Design of thermal systems. New York: McGraw-Hill; 1989.

[17] Balestieri JAP, Correa PB. Multiobjective linear model for pre-feasibility designs of cogeneration systems. Energy 1997;22(5):537-48.

[18] Ferreira EM, Balestieri JAP, Zanardi MA. Optimization analysis of dual-purpose systems. Desalination 2010;250(3):936-44.

[19] Pahl G, Beitz W, Feldhusen J, Grote KH. Engineering design: a systematic approach. Berlin: Springer; 2007.

[20] PTC Mathcad. Best Practices: Requirements Flow-down. 2012. Available at $<$ http://blogs.ptc.com/2012/07/03/best-practice-requirements-flow-down/ > [access: July 17th 2017].

[21] Matelli JA, Bazzo E. On the parameters of performance of combined refrigeration and power plants. Int J Refrig 2013;36(8):2169-75.

[22] Willis Henry H, Loa Kathleen. Measuring the resilience of energy distribution systems. Santa Monica, CA: RAND Corporation; 2015.

[23] Yodo N, Wang P. Resilience allocation for early stage design of complex engineered systems. J Mech Des 2016;138(9):091402.1-091402.10.

[24] Yodo N, Wang P. Engineering resilience quantification and system design implications: a literature survey. J Mech Des 2016;138(11):111408.1-111408.15.

[25] Zhang X, Mahadevan S, Sankararaman S, Goebel K. Resilience-based network design under uncertainty. Reliab Eng Syst Saf 2018;169:364-79.

[26] Rocchetta R, Zio E, Patelli E. A power-flow emulator approach for resilience assessment of repairable power grids subject to weather-induced failures and data deficiency. Appl Energy 2018;210:339-50.

[27] Lin Y, Bie Z. Tri-level optimal hardening plan for a resilient distribution system considering reconfiguration and DG islanding. Appl Energy 2018;210:1266-79.

[28] Ding T, Lin Y, Bie Z, Chen C. A resilient microgrid formation strategy for load restoration considering master-slave distributed generators and topology reconfiguration. Appl Energy 2017;199:205-16.

[29] Sarkar S, Dong A, Henderson JA, Robinson PA. Spectral characterization of hierarchical modularity in product architectures. ASME J Mech Des 2013;136(1). 011006-011006-12. 